\title{
Numerical Investigation of Entropy Generation in a Parabolic Trough Receiver at Different Concentration Ratios
}

\author{
Aggrey Mwesigye, Tunde Bello-Ochende ${ }^{1}$ and Josua P. Meyer \\ Department of Mechanical and Aeronautical Engineering, University of Pretoria, Pretoria \\ Private Bag X20, Hatfield 0028, South Africa.
}

\begin{abstract}
This paper presents results of a numerical analysis of entropy generation in a parabolic trough receiver at different concentration ratios, inlet temperatures and flow rates. Using temperature dependent thermal properties of the heat transfer fluid, the entropy generation due to heat transfer across a finite temperature difference and entropy generation due to fluid friction in the receiver has been determined. Results show a reduction in the entropy generation rate as the inlet temperature increases and an increase in the entropy generation rate as the concentration ratio increases. Results further show that, there is an optimal flow rate at which the entropy generated is a minimum, for every combination of concentration ratio and inlet temperature. The optimal flow rates at which the entropy generated is minimum are $11.974 \times 10^{-3}, 15.395 \times 10^{-3}, 18.817 \times 10^{-3}$, and $22.238 \times 10^{-3}$ and $25.659 \times 10^{-3} \mathrm{~m}^{3} / \mathrm{s}$ when the concentration ratio is 40, 6080100 and 120 respectively, irrespective of the inlet temperature considered. For the range of inlet temperatures, flow rates and concentration ratios considered, the Bejan number, which measures the contribution of entropy generation due to heat transfer irreversibility to the total entropy generation rate is about 1 at low flow rates and is between $0-0.24$ at the highest flow rate.
\end{abstract}

Keywords: Bejan number, Entropy generation, Fluid friction irreversibility, Heat transfer irreversibility, Parabolic trough, Receiver

\footnotetext{
${ }^{1}$ Corresponding author. Tel.: +27 12 4203105; fax: +27 123625124

E-mail address: bello-ochende@up.ac.za
} 


\section{Nomenclature}

$a$

Collector's aperture width, $\mathrm{m}$

$A_{a}$

Collector's aperture area, $\mathrm{m}^{2}$

$A_{c}$

Absorber tube's cross-section area, $\mathrm{m}^{2}$

$A_{r}$

Projected absorber tube area, $\mathrm{m}^{2}$

$B e$

Bejan Number $=$ entropy generated due to heat transfer/total entropy generated

$C_{1}, C_{2}, C_{\mu} \quad$ Turbulent model constants

$c_{f}$

Skin friction coefficient

$c_{p}$

Specific heat capacity, $\mathrm{J} \mathrm{kg}^{-1} \mathrm{~K}^{-1}$

$C_{R}$

Concentration ratio

$d_{g i}$

Inner glass diameter, $\mathrm{m}$

$d_{r i}$

Absorber inner diameter, $\mathrm{m}$

$d_{r o}$

Absorber outer diameter, $\mathrm{m}$

$d_{r}$

Absorber tube diameter, $\mathrm{m}$

D

Hydraulic diameter, $m$

DNI

Direct normal Irradiance, $\mathrm{W} / \mathrm{m}^{2}$

G

Mass flux, $\mathrm{kg} \mathrm{s}^{-1} \mathrm{~m}^{-2}$

$G_{k} \quad$ Generation of turbulence kinetic energy due to mean velocity gradients, $\mathrm{kg} \mathrm{m}^{-1} \mathrm{~s}^{-3}$

$g \quad$ Acceleration due to gravity, $\mathrm{m} \mathrm{s}^{-2}$

$h \quad$ Heat transfer coefficient, $\mathrm{W} \mathrm{m}^{-2} \mathrm{~K}^{-1}$

$I_{b} \quad$ Direct solar radiation. $\mathrm{W} \mathrm{m}^{-2}$

$k \quad$ Turbulent kinetic energy, $\mathrm{m}^{2} \mathrm{~s}^{-2}$

$L \quad$ Receiver length, $\mathrm{m}$

$\dot{m} \quad$ Fluid mass flow rate, $\mathrm{kg} / \mathrm{s}$

$\mathrm{Nu} \quad$ Nusselt number

$N_{s} \quad$ Non-dimensional entropy generation number

$p \quad$ Pressure, $\mathrm{Pa}$

$\dot{q} \quad$ Heat transfer rate, $\mathrm{W}$

$q^{\prime} \quad$ Heat transfer rate per meter length, $\mathrm{W} \mathrm{m}^{-1}$

$q^{\prime \prime} \quad$ Heat flux, $\mathrm{W} \mathrm{m}^{-2}$

$Q \quad$ Heat transfer to the collector, W

$Q^{*} \quad$ Heat transfer from the sun to the collector, $\mathrm{W}$ 


\begin{tabular}{|c|c|}
\hline$Q_{o}$ & Collector heat losses $=\mathrm{Q}^{*}-\mathrm{Q}, \mathrm{W}$ \\
\hline$r$ & Radial position, $\mathrm{m}$ \\
\hline$R$ & Radius, $\mathrm{m}$ \\
\hline $\operatorname{Re}$ & Reynolds number \\
\hline$S$ & Modulus of the mean rate-of-strain tensor, $\mathrm{s}^{-1}$ \\
\hline$S_{i j}$ & Rate of linear deformation tensor, $\mathrm{s}^{-1}$ \\
\hline$S_{g e n}$ & $\begin{array}{l}\text { Entropy generation rate due to heat transfer and fluid friction in the receiver, } \\
\mathrm{W} / \mathrm{K}\end{array}$ \\
\hline$S_{g e n}^{\prime}$ & $\begin{array}{l}\text { Entropy generation due to heat transfer and fluid friction per unit length of the } \\
\text { receiver, W/mK }\end{array}$ \\
\hline$S_{\text {gen,col }}^{\prime}$ & Entropy generation per unit length of the parabolic trough collector, W/K \\
\hline$S^{\prime \prime \prime}{ }_{g e n}$ & Volumetric entropy generation, $\mathrm{W} \mathrm{m} \mathrm{m}^{-3} \mathrm{~K}^{-1}$ \\
\hline$\left(S^{\prime \prime \prime}{ }_{g e n}\right)_{F}$ & Entropy generation due to fluid friction, $\mathrm{W} \mathrm{m} \mathrm{m}^{-3} \mathrm{~K}^{-1}$ \\
\hline$\left(S^{\prime \prime \prime}{ }_{g e n}\right)_{H}$ & Entropy generation due to heat transfer, $\mathrm{W} \mathrm{m}^{-3} \mathrm{~K}^{-1}$ \\
\hline$S_{P R O D, V D}^{\prime \prime \prime}$ & Entropy production by direct dissipation, $\mathrm{W} \mathrm{m}^{-3} \mathrm{~K}^{-1}$ \\
\hline$S_{P R O D, T D}^{\prime \prime \prime}$ & Entropy production by turbulent dissipation, $\mathrm{W} \mathrm{m}^{-3} \mathrm{~K}^{-1}$ \\
\hline$S_{P R O D, T}^{\prime \prime \prime}$ & Entropy production by heat transfer with mean temperatures, $\mathrm{W} \mathrm{m} \mathrm{m}^{-3} \mathrm{~K}^{-1}$ \\
\hline$S_{P R O D, T G}^{\prime \prime \prime}$ & Entropy production by heat transfer with fluctuating temperatures, $\mathrm{W} \mathrm{m}^{-3} \mathrm{~K}^{-1}$ \\
\hline$T$ & Temperature, $\mathrm{K}$ \\
\hline$T_{o}$ & Ambient temperature \\
\hline$T_{r}$ & Reciever temperature, $\mathrm{K}$ \\
\hline$T_{s}$ & Apparent black body temperature of the sun, $\mathrm{K}$ \\
\hline$T *$ & Apparent temperature of the sun as an energy source $=3 / 4 T_{s}, \mathrm{~K}$ \\
\hline$u$ & Velocity, $\mathrm{m} \mathrm{s}^{-1}$ \\
\hline$U_{\infty}$ & Mean flow velocity, $\mathrm{m} \mathrm{s}^{-1}$ \\
\hline$V$ & Volume, $\mathrm{m}^{3}$ \\
\hline$\dot{V}$ & Volumetric flow rate, $\mathrm{m}^{3} / \mathrm{s}$ \\
\hline$u_{i}, u_{j}$ & Averaged velocity components, $\mathrm{m} \mathrm{s}^{-1}$ \\
\hline$u^{\prime}, v^{\prime}, w^{\prime}$ & Velocity fluctuations, $\mathrm{m} \mathrm{s}^{-1}$ \\
\hline$u_{\tau}$ & Friction velocity, $\mathrm{m} \mathrm{s}^{-1}$ \\
\hline$x_{i}, x_{j}$ & Spatial coordinates, $\mathrm{m}$ \\
\hline$x, y, z$ & Cartesian coordinates \\
\hline$y^{+}$ & Dimensionless wall coordinate \\
\hline
\end{tabular}


$-\rho \overline{u_{i}^{\prime} u_{j}^{\prime}} \quad$ Reynolds stresses, $\mathrm{Nm}^{-2}$

Greek letters

$\begin{array}{ll}\alpha & \text { Thermal diffusivity, } \mathrm{m}^{2} \mathrm{~s}^{-1} \\ \alpha_{t} & \text { Turbulent thermal diffusivity, } \mathrm{m}^{2} \mathrm{~s}^{-1} \\ \sigma_{h . t} & \text { Turbulent Prandtl number for energy } \\ \sigma_{\varepsilon} & \text { Turbulent Prandtl number for } \varepsilon \\ \sigma_{k} & \text { Turbulent Prandtl number for } \mathrm{k} \\ \delta_{i j} & \text { Kronecker delta } \\ \varepsilon & \text { Turbulent dissipation rate, } \mathrm{m}^{2} \mathrm{~s}^{-3} \\ \xi & \text { Emissivity } \\ \eta & \text { turbulence model parameter }=S k / \varepsilon \\ \eta_{0} & \text { Optical efficiency, } \% \\ \rho & \text { Density, kg m }{ }^{-3} \\ \tau_{g} & \text { Glass cover transmissivity } \\ \theta & \text { Angular position, degrees } \\ \lambda & \text { Fluid thermal conductivity, } \mathrm{Wm}^{-1} \mathrm{~K}^{-1} \\ \lambda_{e f f} & \text { Heat transfer fluid effective thermal conductivity, } \mathrm{Wm}^{-1} \mathrm{~K}^{-1} \\ \mu & \text { Viscosity, Pa s } \\ \mu_{t} & \text { Turbulent viscosity, Pa s } \\ \mu_{e f f} & \text { Effective viscosity, Pa s } \\ v & \text { Kinematic viscosity, } \mathrm{m}^{2} \mathrm{~s}^{-1}\end{array}$

Subscripts

$\begin{array}{ll}\text { inlet } & \text { Absorber tube inlet } \\ i, j, k & \text { General spatial indices } \\ t & \text { Turbulent } \\ w & \text { Wall } \\ \text { out } & \text { Absorber tube outlet } \\ b u l k & \text { Bulk fluid state } \\ d & \text { Diameter } \\ r o & \text { Absorber tube outer wall } \\ r i & \text { Absorber tube inner wall }\end{array}$




\subsection{Introduction}

Solar resource is the world's most abundant source of energy with the potential to meet a significant portion of the world's energy requirements [1]. For high-temperature requirements, concentrated solar power (CSP) systems are usually used; the solar radiation collecting (receiving) area is larger than the heat collection area which reduces heat losses $[1$, 2]. Parabolic trough collector technology is the most economic and commercially developed of the available concentrated solar power systems [3] especially after the construction of nine Solar Electric Generating Systems (SEGS) in the Mojave Desert in Southern California in the period between 1984 and 1990 [3, 4]. Parabolic trough collectors consist of a reflecting element bent into a parabolic shape which focuses incoming solar radiation onto a tubular receiver or heat collection element together with supporting structures.

A number of studies have been carried out to determine the performance of parabolic trough collectors. Dudley et al. [5, 6] used the AZTRAK rotating platform at SANDIA National Laboratories to study the performance of SEGS LS-2 and industrial solar technology solar collectors respectively. Liu et al. [7] developed an experimental platform to investigate parabolic trough performance. They obtained collector efficiencies between $40-60 \%$ and heat losses of about $220 \mathrm{~W} / \mathrm{m}$ at an absorber-ambient temperature difference of $180{ }^{\circ} \mathrm{C}$. Odeh and Morrison [8] developed a computer model for estimating the transient performance of a solar industrial water heating system. They have shown that for stable operation during transient radiation periods the thermal storage tank size should higher than $14.51 \mathrm{~m}^{-2}$ of the collector area. Lupfert et al. [9] measured the thermal losses of Solel UVAC and Schott PTR70 receivers, Burkholder and Kutscher $[10,11]$ used steady-state tests to determine heat losses for Solel UVAC and Schott's PTR70 parabolic trough receivers respectively. The heat losses were found to increase as the absorber tube temperatures increased [9-11]. For example, the Solel UVAC receiver losses normalised per metre were between 15 and $460 \mathrm{~W} / \mathrm{m}$ at average absorber temperatures between $100{ }^{\circ} \mathrm{C}$ and $450{ }^{\circ} \mathrm{C}$ [10]. Field measurements of glass temperatures were done using a solar-blind infrared camera by Price et al. [12] at the SEGS plants with over 12,000 receivers monitored. Forristall [13] developed a heat transfer model for determining the performance of a parabolic trough receiver implemented in Engineering Equation Solver (EES). The results were comparable with the experimental results of Dudley et al. [5].

For rim angles lower than $90^{\circ}$, only the lower half (lower half being the one facing the reflecting surface) receives concentrated solar radiation. The presence of a differential flux and thus differential temperature in the absorber tube's circumference has been noted in 
studies by [14, 15]. Munoz and Abanades [16] investigated an internally helically finned absorber tube with a view of evening out the non-uniform absorber circumferential temperatures. Meanwhile, other receiver performance enhancements have been studied as reported in the studies by Hegazy [17], for externally finned receiver tubes; Reddy et al. [18], for a receiver with a porous fin and longitudinal fins and Kumar and Reddy [19], for a receiver with a porous disc at different angles.

Renewed interest in CSP in the last two decades has led to increased research and as a result improved plant components have been developed. Price et al. [3] present a review of the research and developments regarding parabolic trough collectors. With these developments, the cost of electricity from parabolic trough collectors has reduced significantly and further cost reductions are deemed possible with improved receiver designs, increased concentrator sizes and improved thermal storage systems [20, 21]. In an attempt to reduce capital costs, increasing the concentration ratios proves a promising alternative since it will lead to reduction in the number of receivers used thus reduced number of drives and controls. On the other hand, increasing the concentration ratios will lead to high heat fluxes and thus increased entropy generation rates due to increased heat transfer irreversibility. Therefore, it becomes necessary to see how increasing the concentration ratios affects the thermal performance of the receiver and the best possible operating flow rates that minimise the entropy generation rates.

The field of entropy generation minimisation has developed after its introduction by Bejan [22] and has become widely applicable to the design and optimisation of thermal systems [23]. Entropy generation minimisation combines the fundamental principles of fluid mechanics, heat transfer and thermodynamics in establishing the irreversibility in system components. Several researchers have studied entropy generation in fluid flow and heat transfer for various system configurations and boundary conditions [24-38]. For solar collectors, Bejan [23] and Kalogirou [1] present a method for determining entropy generation in a solar collector system and the subsequent determination of the optimal collector temperature. The presented method relates the entropy generation to the mass flow rate, the collector's inlet and outlet temperatures, heat losses and solar radiation. Though Kalogirou [1] adapted the method presented by Bejan [23] to imaging collectors, entropy generation due to heat transfer and fluid friction in the receiver of the parabolic collector trough system is not explicitly accounted for.

Kock and Herwig [39] using the Reynolds averaging process, have shown that the entropy generation rate and entropy generation distribution can be determined at any point of 
the fluid. With this approach, use of CFD tools to account for entropy generation in heat transfer devices has become possible [25, 28, 33, 39, and 40]. Moreover, Herwig and Kock [40] presented and compared results of the direct method based on numerical method and expressions they derived in [39] and the indirect method based on the analytical expression for entropy generation in turbulent flows presented in Bejan [23]. They noted that as conditions differ from simple pipe flow with constant heat flux, the two methods give values that differ significantly. The direct method is found to be superior and robust when complex geometries and complex thermal boundary conditions are encountered. Apart from Bejan [23] and Kalogirou [1] who have demonstrated the use of the second law for analysis of solar collectors and imaging solar collectors respectively, no studies have been done on entropy generation due heat transfer and fluid flow in the parabolic trough receiver.

Therefore, the main objective of this study is to numerically analyse entropy generation due to heat transfer and fluid flow in a parabolic trough receiver at different values of concentration ratio, inlet temperatures and Reynolds numbers. Concentration ratios 40, 60, 80, 100 and 120, inlet temperatures 350, 400, 450, 500 and $650 \mathrm{~K}$ and Reynolds numbers from $1.19 \times 10^{4}-1.92 \times 10^{6}$ were selected. The Reynolds numbers used depend on both the flow rate and inlet temperature used. For example, the Reynolds number is $1.19 \times 10^{4}$ at an inlet temperature of $350 \mathrm{~K}$ and $1.1 \times 10^{5}$ at an inlet temperature of $650 \mathrm{~K}$ when the flow rate is $2.566 \times 10^{-3} \mathrm{~m}^{3} / \mathrm{s}$, the Reynolds number increases to $1.95 \times 10^{5}$ at an inlet temperature of $350 \mathrm{~K}$ and $1.92 \times 10^{6}$ at an inlet temperature of $650 \mathrm{~K}$ when the flow rate is $42.76 \times 10^{-3} \mathrm{~m}^{3} / \mathrm{s}$.

\subsection{Physical Model}

The heat collection element of the parabolic trough system is fundamental to the performance of the entire system. To ensure high efficiencies, the heat collection element consists of a steel absorber tube enclosed in a glass jacket, which is evacuated to pressures below the Knudsen gas conduction level (0.013 Pa) [3] to suppress convection heat losses. Receivers are further made with absorber tubes which are selectively coated to ensure higher absorptivity of incoming solar radiation and low emissivity of infrared radiation. Because current heat transfer fluids decompose when temperatures exceed about $400{ }^{\circ} \mathrm{C}$ [41], getter material is provided to absorb the hydrogen formed inside the receiver's annulus since its accumulation drastically increases heat losses [13]. Fig. 1 shows a receiver [3] together with the improved bellow design of the new commercially available SCHOTT receiver [42]. 


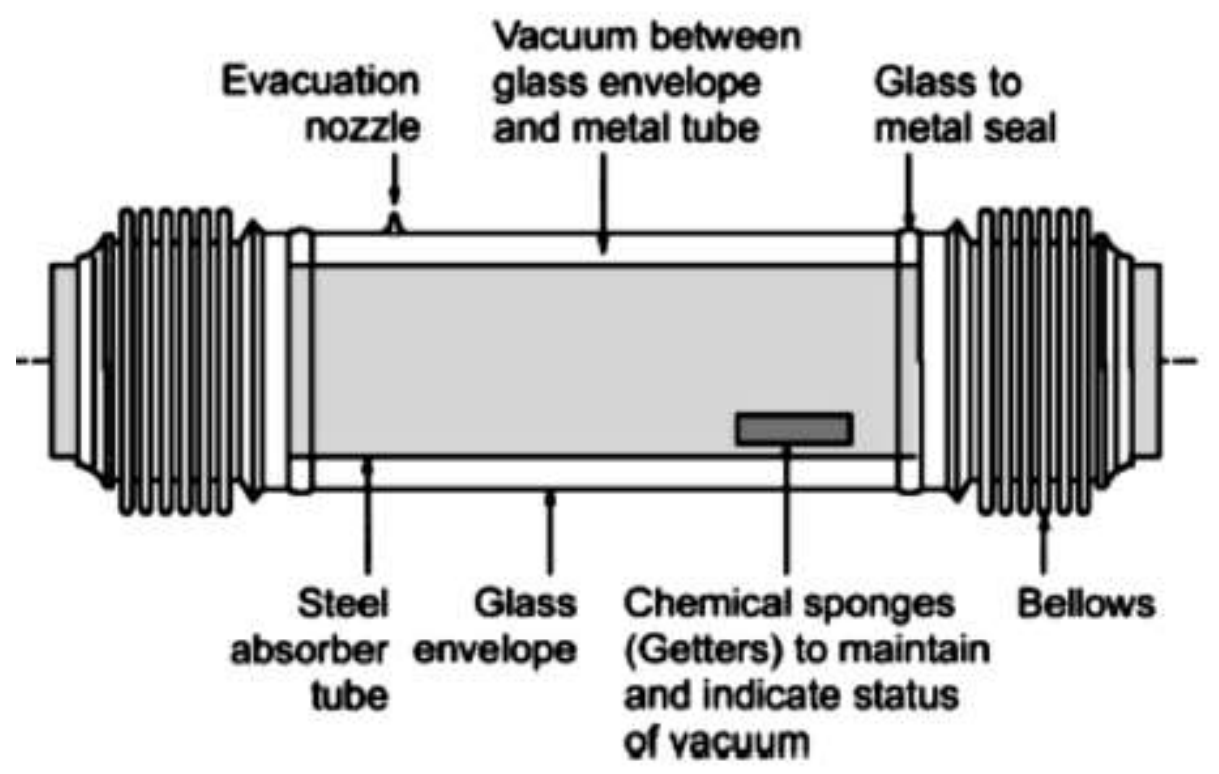

(a)

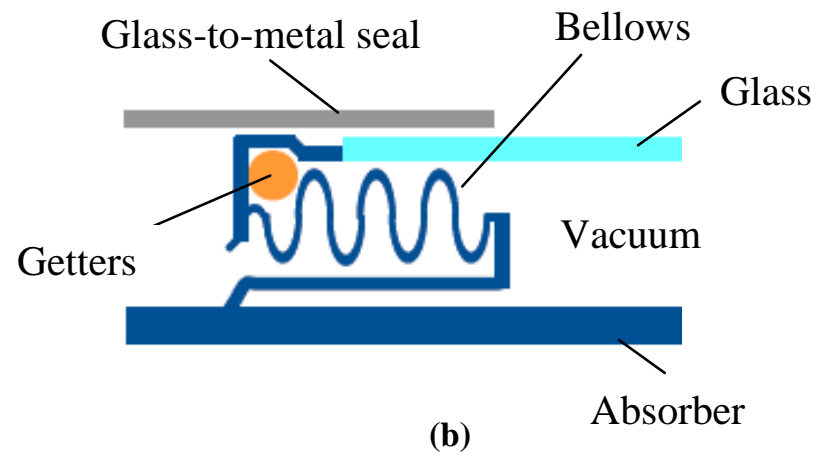

Fig. 1. (a) Receiver (b) Schott's receiver bellow design

In this study, the simplified model of the parabolic trough receiver being analysed is shown in Fig. 2. The space between the absorber and the glass cover is considered evacuated such that only radiation heat losses take place. The concentration ratio is defined as $C_{R}=$ $A_{a} / A_{r}$ where $A_{a}$ is the area of the collector's aperture and $A_{r}$ is the projected area of the absorber tube. Because of symmetry, only half of the receiver was considered.

The upper half receives direct solar radiation, whereas the lower half receives concentrated solar radiation, $\tau_{g}$ is the transmissivity of the glass cover, $\eta_{o}$ is the optical efficiency and $I_{b}$ is the direct solar radiation. The emissivity of the absorber tube varies with temperature according to $\xi=0.00031 T_{r o}-0.0216[13]$. 

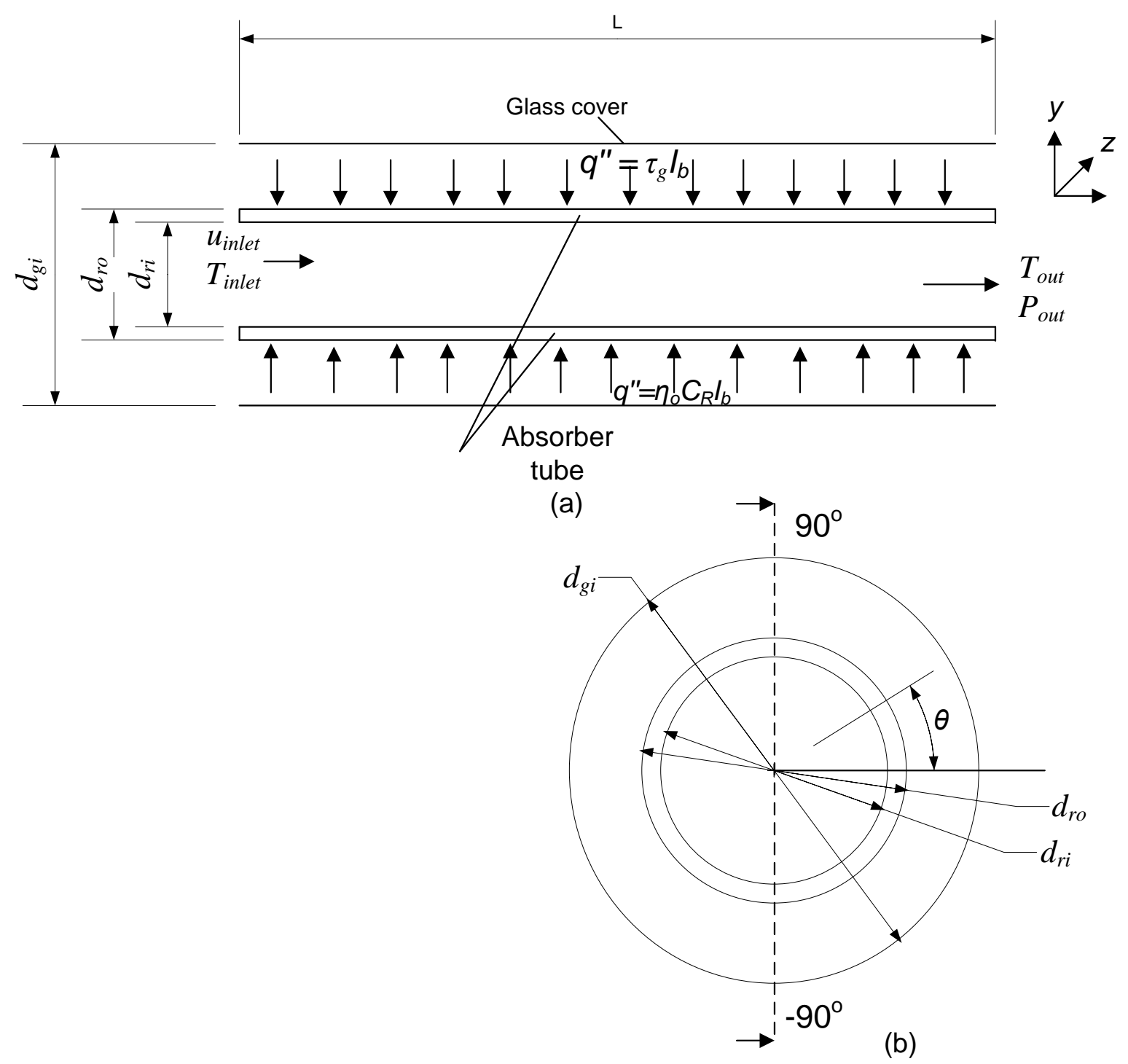

Fig. 2. Computational domain

The geometrical parameters for the considered receiver are shown in Table 1.0

Table 1.0 Geometrical parameters

\begin{tabular}{lc}
\hline Parameter & Value \\
\hline$d_{g i}(\mathrm{~cm})$ & 11.5 \\
$d_{r i}(\mathrm{~cm})$ & 6.6 \\
$d_{r o}(\mathrm{~cm})$ & 7 \\
$L(\mathrm{~m})$ & 4 \\
$a(\mathrm{~m})$ & 5 \\
$\eta_{o}(\%)$ & 73.2 \\
$I_{b}\left(\mathrm{~W} / \mathrm{m}^{2)}\right.$ & 1000 \\
$C_{R}$ & $40,60,80,100,120$ \\
\hline
\end{tabular}




\subsection{Governing Equations and Boundary Conditions}

\subsection{Governing Equations}

The governing equations for steady-state and three-dimensional turbulent flow are the continuity, momentum and energy equations given by;

Continuity

$$
\frac{\partial\left(\rho u_{i}\right)}{\partial x_{i}}=0
$$

Momentum equation

$$
\frac{\partial}{\partial x_{j}}\left(\rho u_{i} u_{j}\right)=-\frac{\partial p}{\partial x_{i}}+\frac{\partial}{\partial x_{j}}\left[\mu_{e f f}\left(\frac{\partial u_{i}}{\partial x_{j}}+\frac{\partial u_{j}}{\partial x_{i}}\right)-\frac{2}{3} \mu_{e f f} \frac{\partial u_{i}}{\partial x_{i}} \delta_{i j}-\rho \overline{u_{i}^{\prime} u_{j}^{\prime}}\right]
$$

Energy equation

$$
\begin{aligned}
\frac{\partial}{\partial x_{j}}\left(\rho u_{j} c_{p} T\right)= & \frac{\partial}{\partial x_{j}}\left(\lambda \frac{\partial T}{\partial x_{j}}+\frac{\mu_{t}}{\sigma_{h, t}} \frac{\partial\left(c_{P} T\right)}{\partial x_{j}}\right)+u_{j} \frac{\partial p}{\partial x_{j}} \\
+ & {\left[\mu_{e f f}\left(\frac{\partial u_{i}}{\partial x_{j}}+\frac{\partial u_{j}}{\partial x_{i}}\right)-\frac{2}{3} \mu_{e f f} \frac{\partial u_{i}}{\partial x_{i}} \delta_{i j}-\rho \overline{u_{i}^{\prime} u_{j}^{\prime}}\right] \frac{\partial u_{i}}{\partial x_{j}} }
\end{aligned}
$$

Additional terms appearing in these equations represent the turbulence effects and the Reynolds stresses $-\rho \overline{u_{i}^{\prime} u_{j}^{\prime}} . \quad u_{i}, u_{j}$ are the time-averaged velocity components in the $i$ - and $j$ directions respectively and $T$ the time-averaged temperature. The effective viscosity is given by $\mu_{\text {eff }}=\mu+\mu_{t}$ and $\lambda$ is the fluid thermal conductivity. The most common approach for representation of Reynolds stresses is the Boussinesq approach, where the Reynolds stresses are related to the mean velocity gradients through

$$
-\rho \overline{u_{i}^{\prime} u_{j}^{\prime}}=2 \mu_{t} S_{i j}-\frac{2}{3}\left(\rho k+\mu_{t} \frac{\partial u_{k}}{\partial x_{k}}\right) \delta_{i j}
$$

Such that

$$
-\rho \overline{u_{i}^{\prime} u_{j}^{\prime}}=\mu_{t}\left(\frac{\partial u_{i}}{\partial x_{j}}+\frac{\partial u_{j}}{\partial x_{i}}\right)-\frac{2}{3}\left(\rho k+\mu_{t} \frac{\partial u_{k}}{\partial x_{k}}\right) \delta_{i j}
$$

Where $\mathrm{k}$ is the turbulent kinetic energy per unit mass given by

$$
k=\frac{1}{2}\left(\overline{u^{\prime 2}}+\overline{v^{\prime 2}}+\overline{w^{\prime 2}}\right)
$$

This approach has relatively lower computation cost requirements compared to the Reynolds stress transport model approach, which solves transport equations for each of the terms in the Reynolds stress tensor. A number of turbulence models based on the Boussinesq approach have been developed, the k- $\varepsilon$ models being the widely used and validated models for most flows [43]. For this study the realisable $k-\varepsilon$ model was adopted [44]. The additional equations 
required for the transport of turbulent kinetic energy and turbulent dissipation rates in the realisable $k-\varepsilon$ model [44] are;

For $k$

$\frac{\partial}{\partial x_{j}}\left(\rho k u_{j}\right)=\frac{\partial}{\partial x_{j}}\left[\left(\mu+\frac{\mu_{t}}{\sigma_{k}}\right) \frac{\partial k}{\partial x_{j}}\right]+G_{k}-\rho \varepsilon$

And $\varepsilon$

$\frac{\partial}{\partial x_{j}}\left(\rho \varepsilon u_{j}\right)=\frac{\partial}{\partial x_{j}}\left[\left(\mu+\frac{\mu_{t}}{\sigma_{\varepsilon}}\right) \frac{\partial \varepsilon}{\partial x_{j}}\right]+\rho C_{1} S \varepsilon-\rho C_{2} \frac{\varepsilon^{2}}{k+\sqrt{v \varepsilon}}$

Where

$G_{k}$ represents production of turbulent kinetic energy and is modelled the same way for all the $k-\varepsilon$ models as

$G_{k}=-\rho \overline{u_{i}^{\prime} u_{j}^{\prime}} \frac{\partial u_{j}}{\partial x_{i}}$

Consistent with the Boussinesq's hypothesis

$G_{k}=\mu_{t} S^{2}$

The eddy viscosity is given by

$\mu_{t}=\rho C_{\mu} \frac{k^{2}}{\varepsilon}$

Unlike in other $k-\varepsilon$ models $C_{\mu}$ is not constant and is determined from empirical relations. Detailed determination of $C_{\mu}$ is given in [44]. The model constants for the $k-\varepsilon$ realizable model are: $C_{1}=\max \left[0.43, \frac{\eta}{\eta+5}\right], \eta=S \frac{k}{\varepsilon}, S \equiv \sqrt{2 S_{i j} S_{i j}} \quad, \mathrm{C}_{2}=1.9, \sigma_{\mathrm{k}}=1, \sigma_{\varepsilon}=1.2, \mathrm{~S}_{\mathrm{ij}}$ represents the rate of linear deformation of a fluid element. In total, there are nine components in three dimensions, of which three are linear elongation deformation components and six are shearing and deformation components [43]

$$
S_{i j}=\frac{1}{2}\left(\frac{\partial u_{i}}{\partial x_{j}}+\frac{\partial u_{j}}{\partial x_{i}}\right)
$$

\subsection{Boundary Conditions}

Since only radiation heat losses take place between the absorber tube and glass cover, this exchange was modelled by imposing a radiation boundary condition on the absorber tube and the glass cover taken to be at $300 \mathrm{~K}$. In addition, due to symmetry only half of the receiver was considered and the end effects as well as the effect of the receiver's supports were considered negligible. In view of this, the boundary conditions (Fig. 2) used are;

- At the inlet, a uniform velocity is used 


$$
u_{i}=u_{\text {inlet },} \quad T=T_{\text {inlet }}, \quad \text { at } \quad 0 \leq r \leq \frac{d_{r i}}{2},-90^{\circ} \leq \theta \leq 90^{\circ}
$$

- At the outlet,

$$
0 \leq r \leq \frac{d_{r i}}{2},-90^{\circ} \leq \theta \leq 90^{\circ}, x=L
$$

a zero pressure gradient is applied at

- No-slip condition is used on the absorber inner walls

$$
u=0 \quad \text { at } \quad r=\frac{d_{r i}}{2},-90^{\circ} \leq \theta \leq 90^{\circ}, 0 \leq x \leq L
$$

- The outer walls of the absorber tube are subject to a uniform heat flux.

The upper half of the absorber outer wall is subject to direct solar flux

$$
q^{\prime \prime}=\tau_{g} I_{b} \quad \text { at } \quad r=\frac{d_{r o}}{2}, \quad 0^{o} \leq \theta \leq 90, \quad 0 \leq x \leq L
$$

The lower half of the absorber tube receives concentrated solar flux

$$
q^{\prime \prime}=\eta_{o} \times C_{R} \times I_{b} \text { at } r=\frac{d_{r o}}{2},-90^{\circ} \leq \theta \leq 0, \quad 0 \leq x \leq L
$$

where $\tau_{g}$ is the glass transmissivity, $I_{b}$ is the direct solar irradiance and $\eta_{o}$ is the collector optical efficiency.

\subsection{Entropy Generation}

Solving Equations (1-12) gives the distributions for velocity, temperature, pressure and turbulent quantities inside the absorber tube. Since entropy for single-phase flow is a function of temperature and pressure, it can be obtained in the post-processing phase of a CFD simulation. The entropy generation in flow that is turbulent can be obtained from equations given by [40]. Entropy generation is from heat transfer irreversibility $\left(S^{\prime \prime \prime}{ }_{g e n}\right)_{H}$ and fluid friction irreversibility $\left(S^{\prime \prime \prime}{ }_{g e n}\right)_{F}$ given as

$$
S_{g e n}^{\prime \prime \prime}=\left(S_{g e n}^{\prime \prime \prime}\right)_{F}+\left(S_{g e n}^{\prime \prime \prime}\right)_{H}
$$

The entropy generation due to fluid friction irreversibility is given by

$$
\left(S_{g e n}^{\prime \prime \prime}\right)_{F}=S_{P R O D, V D}^{\prime \prime \prime}+S_{P R O D, T D}^{\prime \prime \prime}
$$

where

$$
S_{P R O D, V D}^{\prime \prime \prime}=\frac{\mu}{T}\left(\frac{\partial u_{i}}{\partial x_{j}}+\frac{\partial u_{j}}{\partial x_{i}}\right) \frac{\partial u_{i}}{\partial x_{j}}
$$

is the entropy production by direct dissipation and 
$S_{P R O D, T D}^{\prime \prime \prime}=\frac{\rho \varepsilon}{T}$

is the entropy production by indirect (turbulent) dissipation.

The entropy generation due to heat transfer irreversibility is given by

$\left(S_{g e n}^{\prime \prime \prime}\right)_{H}=S_{P R O D, T}^{\prime \prime \prime}+S_{P R O D, T G}^{\prime \prime \prime}$

where

$S_{P R O D, T}^{\prime \prime \prime}=\frac{\lambda}{T^{2}}(\nabla T)^{2}$

is the entropy production by heat transfer with mean temperatures and

$S_{P R O D, T G}^{\prime \prime \prime}=\frac{\alpha_{t}}{\alpha} \frac{\lambda}{T^{2}}(\nabla T)^{2}$

is the entropy production by heat transfer with fluctuating temperatures. In Eq.19, $\alpha$ and $\alpha_{t}$ are the thermal diffusivities.

Eqs. (13-19) describe the direct method of entropy generation [40] whereas the indirect method of entropy determination is according to the correlation given by [23]. The entropy generation per unit length $S_{\text {gen }}^{\prime}$ is given as

$$
S_{g e n}^{\prime}=\frac{q^{\prime 2}}{\pi \lambda T_{b u l k}^{2} N u}+\frac{32 \dot{m}^{3} c_{f}}{\pi^{2} \rho^{2} T_{b u l k} D^{5}}
$$

Where $q^{\prime}$ is the heat transfer rate per unit length, $N u=h D / \lambda$ with $h=q^{\prime \prime} /\left(T_{w^{-}}-T_{b u l k}\right), c_{f}=(-$ $d p / d x) \rho D / 2 G^{2}$, with $G=4 \dot{m} / \pi D^{2}$ and $T_{\text {bulk }}$ is the bulk fluid temperature $\left(T_{\text {inlet }}+T_{\text {outlet }}\right) / 2$. The above equation follows from the expression used by Bejan [23] in determining the optimum diameter of a tube for minimum entropy generation subject to the constraint of fixed surface area. For a fluid occupying a volume $\mathrm{V}$, the volume integral entropy generation rate is given by

$$
S_{g e n}=\iiint_{V} S_{g e n}^{\prime \prime \prime} d V
$$

The Bejan number which measures the contribution of heat transfer irreversibility to the total entropy generation, is defined as $B e=\left(S^{\prime \prime \prime}{ }_{\text {gen }}\right)_{H} / S^{\prime \prime \prime}{ }_{\text {gen }}$. When $B e=1$, the heat transfer irreversibility is dominant and when $B e=0$, fluid friction irreversibility is dominant.

The direct and indirect methods give similar results for simple cases but as the flow becomes complex, the results of the indirect methods differ significantly from those obtained by the direct method [40]. The variation between analytical and numerical results is also reported by [28] for an incompressible viscous flow and heat transfer in curved pipes. 


\subsection{Solution Procedure}

The numerical solution was implemented in a commercial software package ANSYS ${ }^{\circ} 13$. The geometry was built in ANSYS design modeler and the computational grid created in ANSYS meshing. The numerical solution is obtained in ANSYS FLUENT, which uses a finite volume method for solving the governing continuity, momentum, energy and $k-\varepsilon$ model equations. The SIMPLE algorithm put forward by Patankar and Spalding [45] was used for coupling the pressure and velocity. Second-order upwind schemes were employed for integrating the governing equations together with the boundary conditions over the computational domain. Given the need to capture a high resolution of gradients near the wall, the enhanced wall functions [44] were used with $y^{+} \approx 1$ used in all simulations. Where $y^{+}=$ $y \mu_{\tau} / v, v$ is the fluid's kinematic viscosity, $y$ is the distance from the wall, and $u_{\tau}$ is the friction velocity given by $u_{\tau}=\sqrt{ }\left(\tau_{w} / \rho\right)$. To predict the near wall cell size, the distance y was calculated as $=y^{+} \mu / u_{\tau} \rho$. For internal flow, $\tau_{w}=c_{f} \rho U_{\infty}^{2} / 2$; where $c_{f}=0.079 R e_{d}^{-0.25}$. Convergence was obtained with scaled residuals of mass, momentum, turbulent kinetic energy and turbulence dissipation rate less than $10^{-4}$ while the energy residuals were less than $10^{-7}$. Convergence was also monitored using the convergence history of volume-averaged entropy generation in the absorber tube. The solution was considered converged when the volume-averaged entropy generation remained constant for more than 200 successive iterations.

Mesh independence studies for several refinements of the mesh were carried out with the volume integral entropy generation as a monitored quantity. A total of 165, 000 mesh elements were found to ensure a mesh independent solution.

Syltherm 800 [46] was used as the absorber tube heat transfer fluid, its properties were entered as temperature dependent polynomials for specific heat capacity $\left(c_{p}\right)$, density $(\rho)$ and thermal conductivity $(\lambda)$ and piece-wise temperature dependent polynomial for viscosity $(\mu)$ as determined from the manufacturer's specifications [46] given by Eqs. (21-25). Sample thermal properties of Syltherm 800 at $T_{\text {inlet }}=400 \mathrm{~K}, 550 \mathrm{~K}$ and $650 \mathrm{~K}$ are shown in Table 2.0. The absorber tube material is stainless steel with a temperature dependent thermal conductivity [10]

$$
\begin{aligned}
& \text { For } 233.15 \leq T \leq 673.15 \mathrm{~K} \\
& c_{p}=1.10787+1.70736 \times 10^{-3} \mathrm{~T} \quad(\mathrm{~kJ} / \mathrm{kgK}) \\
& \rho=1.2691 \times 10^{3}-1.52115 T+1.79133 \times 10^{-3} \mathrm{~T}^{2}-1.67145 \times 10^{-6} T^{3} \quad\left(\mathrm{~kg} / \mathrm{m}^{3}\right)
\end{aligned}
$$


$\lambda=1.90134 \times 10^{-1}-1.88053 \times 10^{-4} T(W / m K)$

For $233.15 \leq T \leq 343 \quad K$

$$
\begin{gathered}
\mu=5.14887 \times 10^{4}-9.61656 \times 10^{2} T+7.50207 T^{2}-3.12468 \times 10^{-2} T^{3}+7.32194 \times 10^{-5} T^{4} \\
-9.14636 \times 10^{-8} T^{5}+4.75624 \times 10^{-11} T^{6} \quad(\text { mPa.s })
\end{gathered}
$$

For $343 \leq T \leq 673.15 K$

$$
\begin{gathered}
\mu=9.88562 \times 10^{1}-7.30924 \times 10^{-1} T+2.21917 \times 10^{-3} T^{2}-3.42377 \times 10^{-6} T^{3} \\
+2.66836 \times 10^{-9} T^{4}-8.37194 \times 10^{-13} T^{5} \quad(\text { mPa.s })
\end{gathered}
$$

Table 2.0: Syltherm 800 thermal properties at $T_{\text {inlet }}=400 \mathrm{~K}, 550 \mathrm{~K}$ and $650 \mathrm{~K}$

\begin{tabular}{cccc}
\hline Thermal property & & $T_{\text {inlet }}(\mathrm{K})$ & \\
& $400 \mathrm{~K}$ & $550 \mathrm{~K}$ & $650 \mathrm{~K}$ \\
\hline Specific heat capacity $\left(c_{p}\right), \mathrm{J} / \mathrm{kg} \mathrm{K}$ & 1791.43 & 2047.318 & 2218.26 \\
Density $(\rho), \mathrm{kg} / \mathrm{m}^{3}$ & 840.06 & 696.0074 & 577.70 \\
Thermal conductivity $(\lambda), \mathrm{W} / \mathrm{m} \mathrm{K}$ & 0.114845 & 0.086661 & 0.067833 \\
Viscosity $(\mu)$, Pa.s & 0.002163 & 0.000555 & 0.000284 \\
\hline
\end{tabular}

\subsection{Results}

\subsection{Model Validation}

The results of the numerical model were validated with experimental data done on parabolic trough receivers. For heat losses the study of Burkholder and Kutscher [10] was used and for temperature gain the study of Dudley et al. [5]. Fig.3 shows the validation of the present model heat losses with test results by Burkholder and Kutscher [10]. The agreement is within less than $10 \%$ except for the last point when absorber temperatures become high. Comparing the present model against the test data by Dudley et al. [5], it is also shown in Fig. 4 that a percentage deviation of less than $11 \%$ is achieved.

The indirect method of determining entropy generation as proposed by Bejan [23] was used to validate the results obtained in this study by the direct method. This same validation was used by [40] to validate the proposed expressions for the direct method of determining entropy generation. The example studied by Bejan [23] was reproduced here for validation purposes. A pipe of diameter $D$ with fully developed turbulent flow of water is heated by a constant heat flux of $10^{5} \mathrm{~W} / \mathrm{m}^{2}$ over its length $L$, so that the temperature is raised from $300 \mathrm{~K}$ 


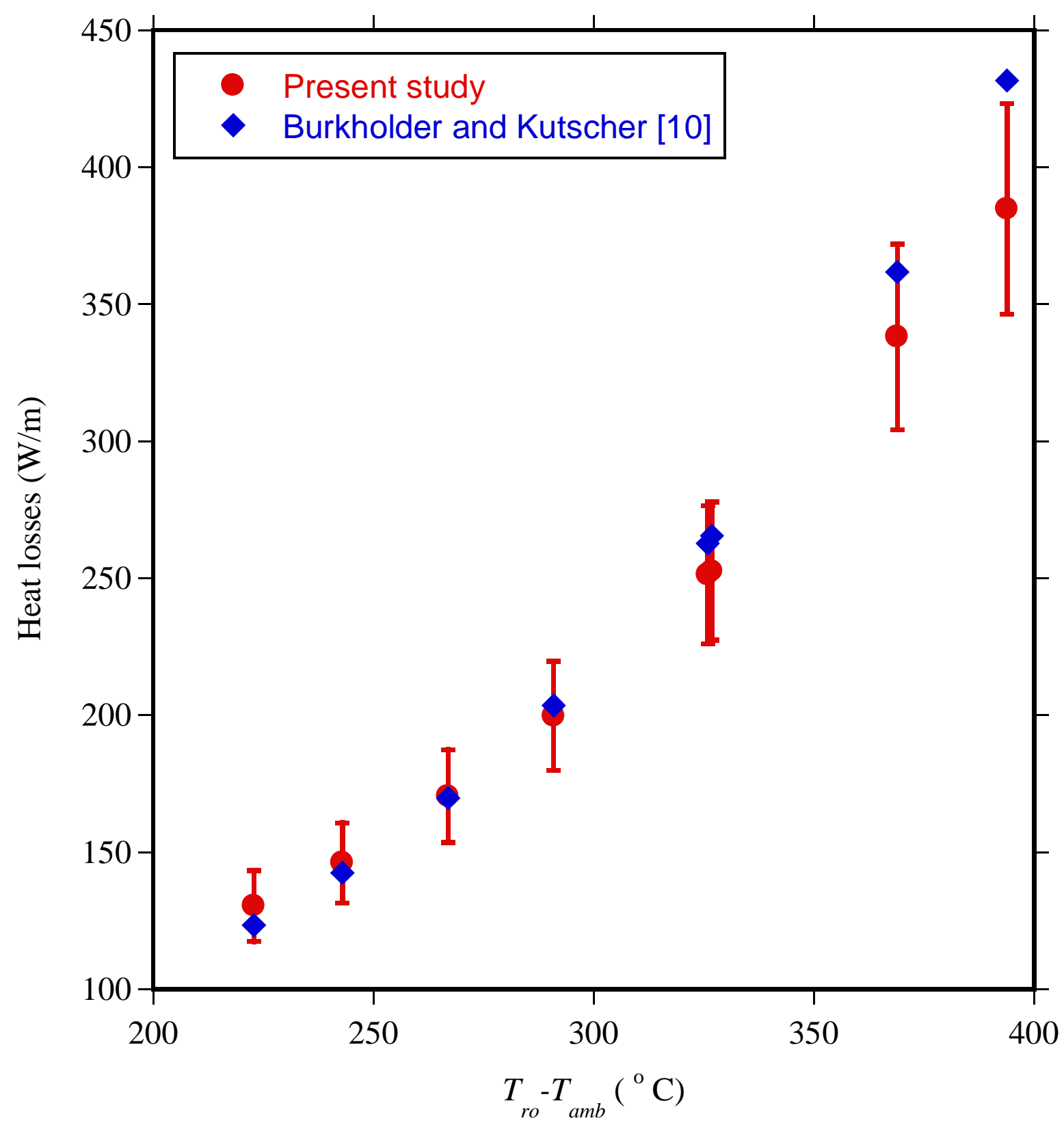

Fig. 3. Comparison of present model heat losses with Burkholder and Kutscher [10]

to $310 \mathrm{~K}$. The values of $D$ and $L$ are varied for a constant heat transfer surface area $\pi D L=$ $0.42 \mathrm{~m}^{2}$.

It is shown in Fig. 5 that the direct method and indirect method give almost similar values except for cases of low Reynolds numbers. Although the direct and indirect methods give similar results for simple cases of pipe configurations under different operating conditions or complex geometries, the direct method gives more accurate results of entropy generation [40]. Shown in Fig. 6, is the entropy generation in the absorber tube at constant heat flux, with the direct and indirect method. If the actual heat flux on the receiver is considered (concentrated heat flux on the lower half and direct solar radiation on the upper 
half) the values of entropy generation differ greatly. The optimum operating conditions also differ slightly.

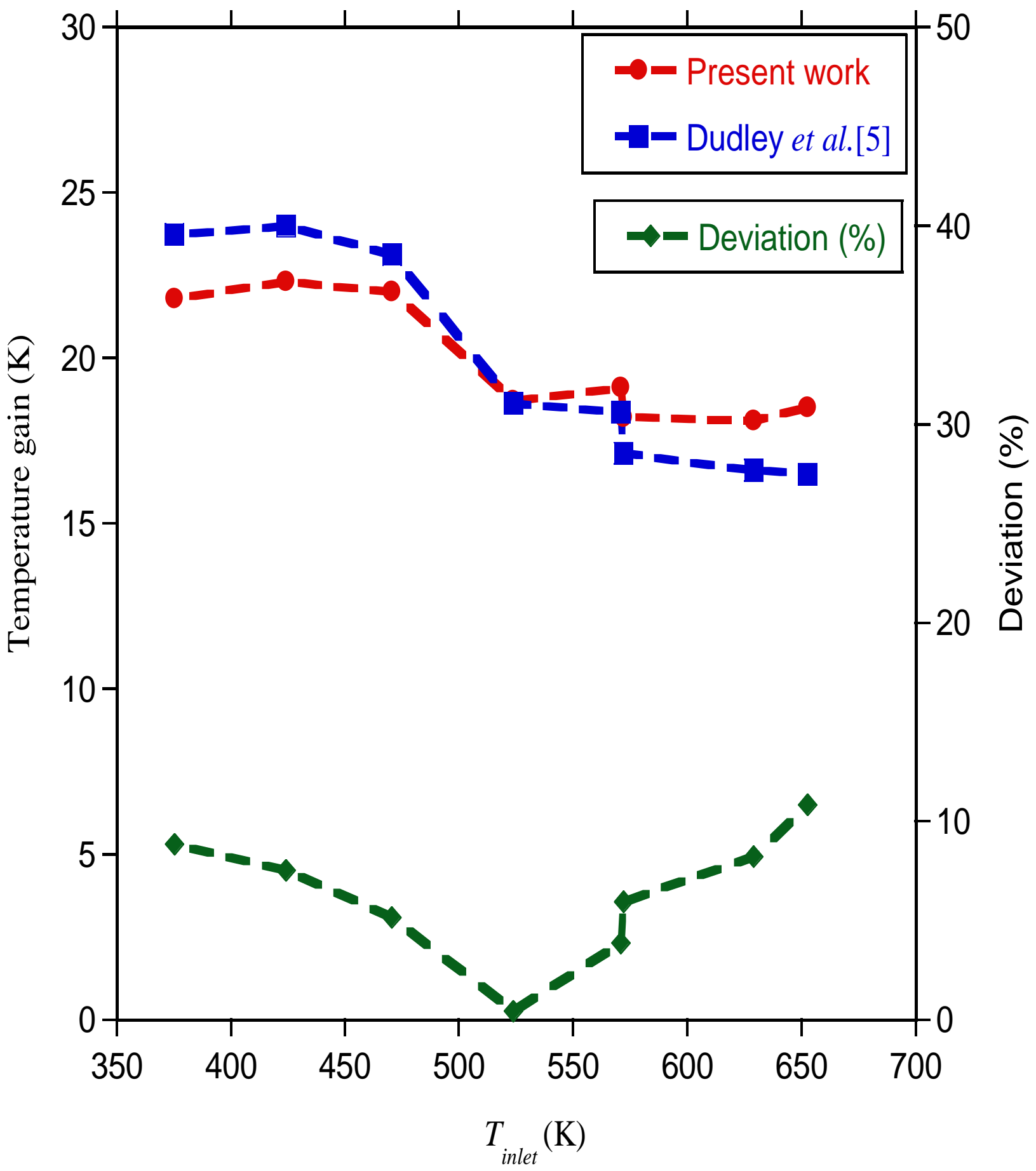

Fig. 4. Validation of present model with experimental data Dudley et al. [5] 


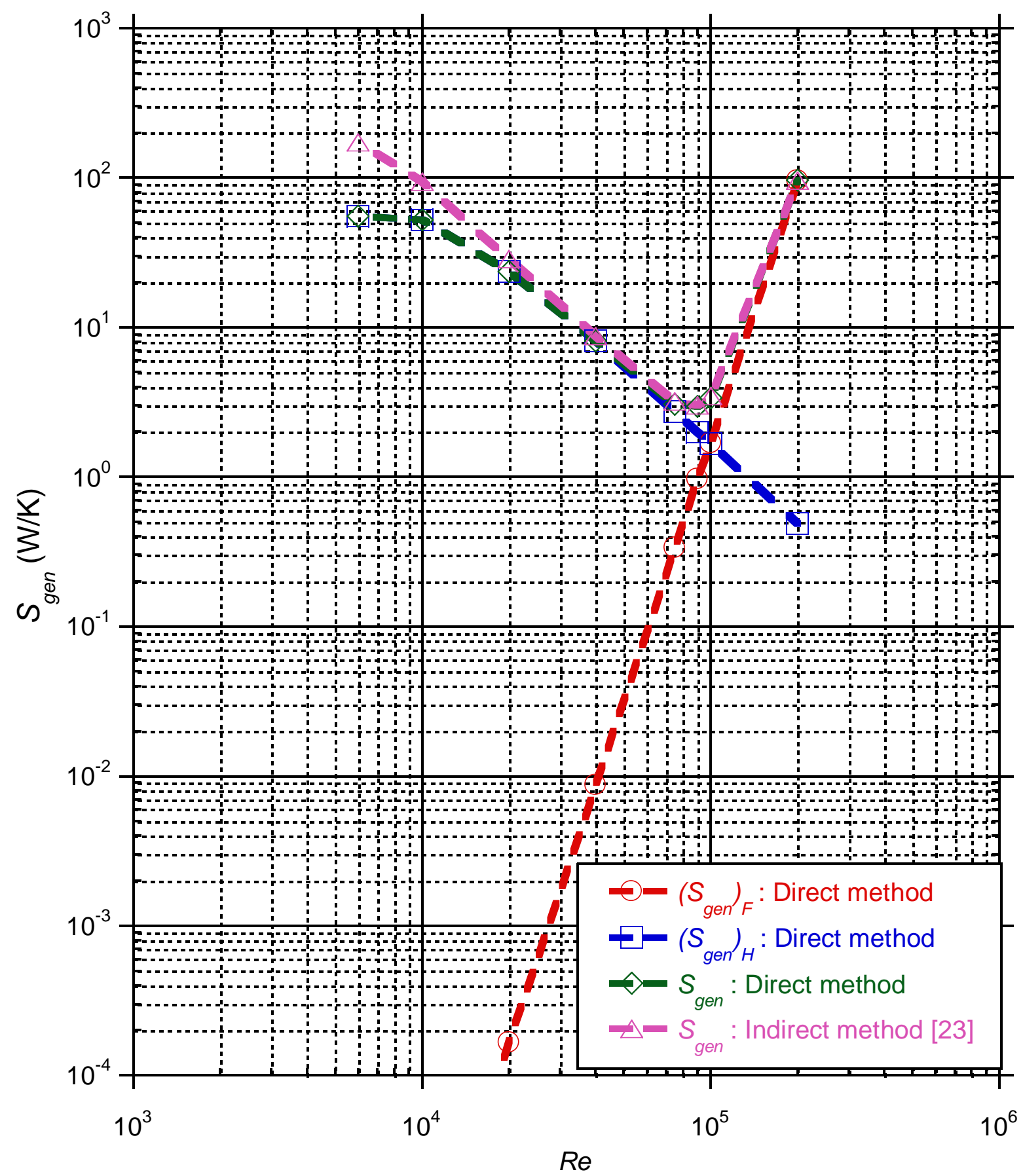

Fig. 5. Validation of entropy generation rates with the indirect method Bejan [23] 


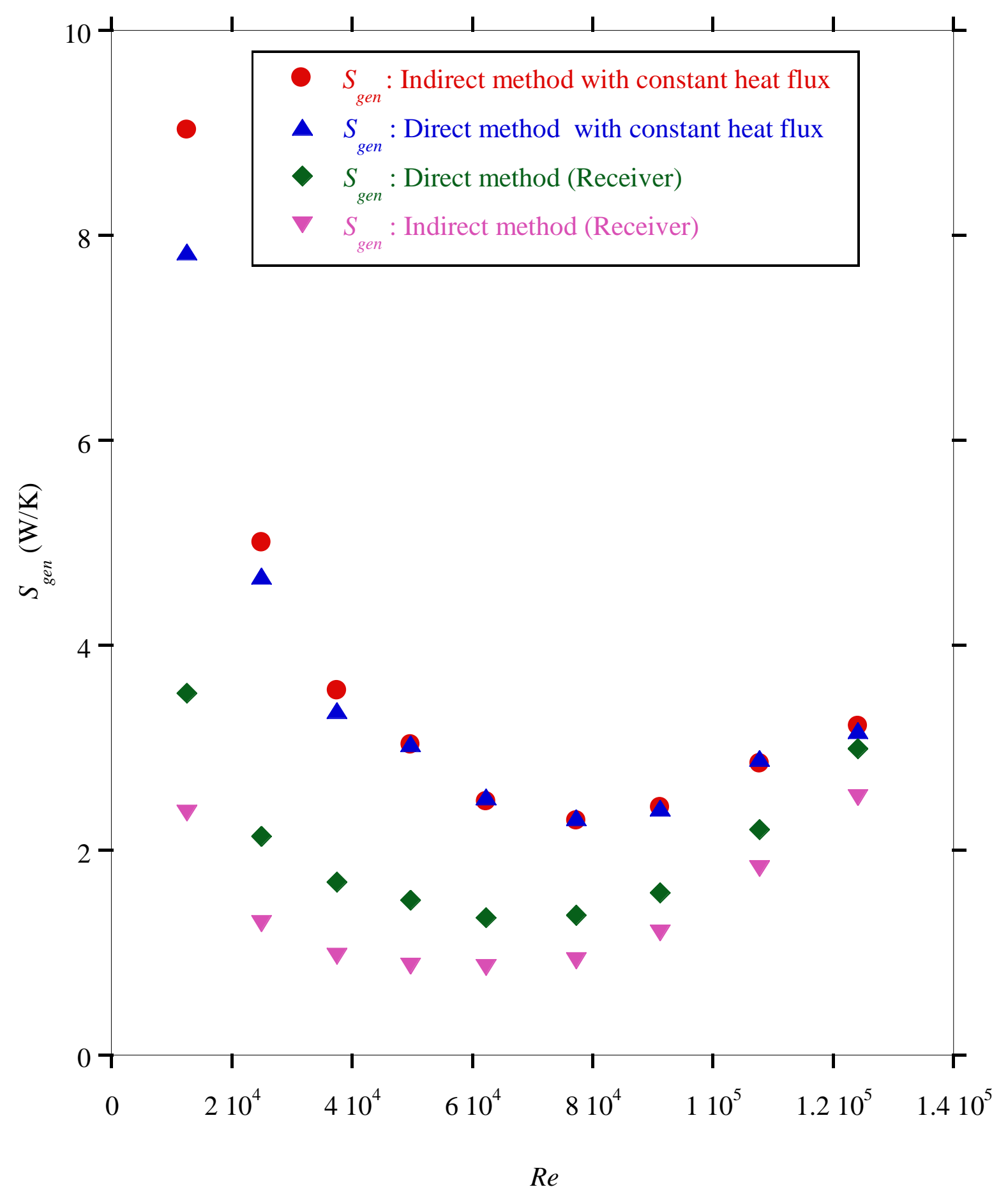

Fig. 6. Entropy generation in an absorber tube with constant flux and on a receiver with a concentrated flux on the lower half and direct solar radiation on the upper half $\left(T_{i n}=350 \mathrm{~K}, C_{R}=40, \mathrm{DNI}=1000\right.$ $\mathbf{W} / \mathbf{m}^{2}$ )

\subsection{Distribution of Entropy Generation in the Absorber Tube}

To ensure the correct prediction of entropy generation close to walls, the value of $y^{+} \approx$ 1 was used in all simulations. To study the distribution of entropy in the absorber tube, a concentration ratio of 80 , inlet fluid temperature of $500 \mathrm{~K}$ and a Reynolds number of $2.69 \times$ 


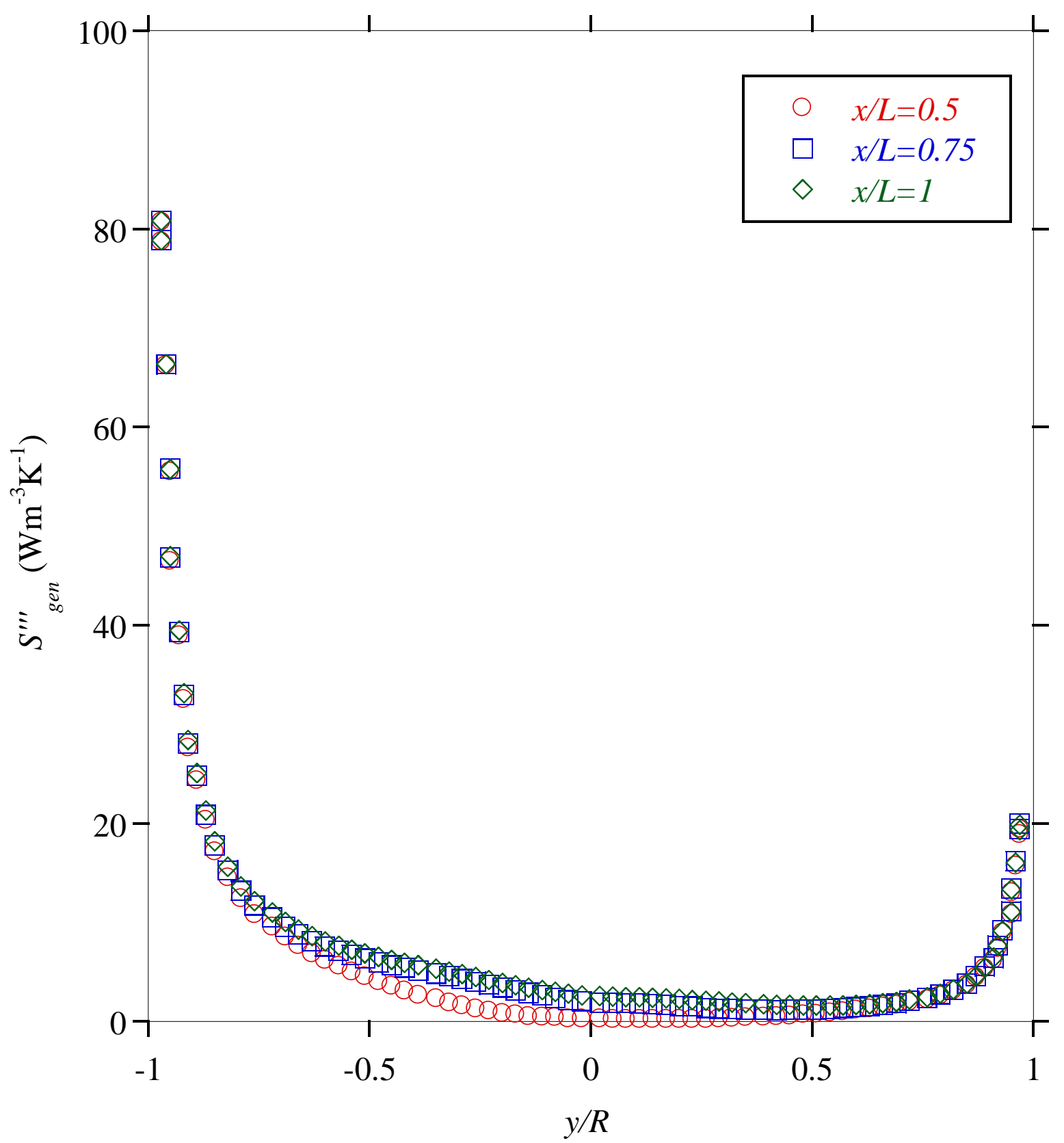

Fig. 7. Entropy generation along the absorber tube's radial direction; for the lower half $y / R<0$ and for the upper half $y / R>0$

$10^{5}$ were used. Entropy generation at different locations in the absorber tube's streamwise direction, $x / L=0.5,0.75$ and radial positions $y / R$ were determined. $(y / R=0$ represents the centre of the tube, $y / R=1$ the absorber tube's upper wall and $y / R=-1$ the absorber tube's lower wall at any given value of $x / L$ ). As shown in Fig. 7, the entropy generation is higher close to the walls given the high temperature and velocity gradients in the near-wall regions. The figure also shows that the entropy generation is higher on the lower half of the absorber tube $(y / R=-1)$ than on the upper half $(y / R=1)$ since the lower half is the one receiving 


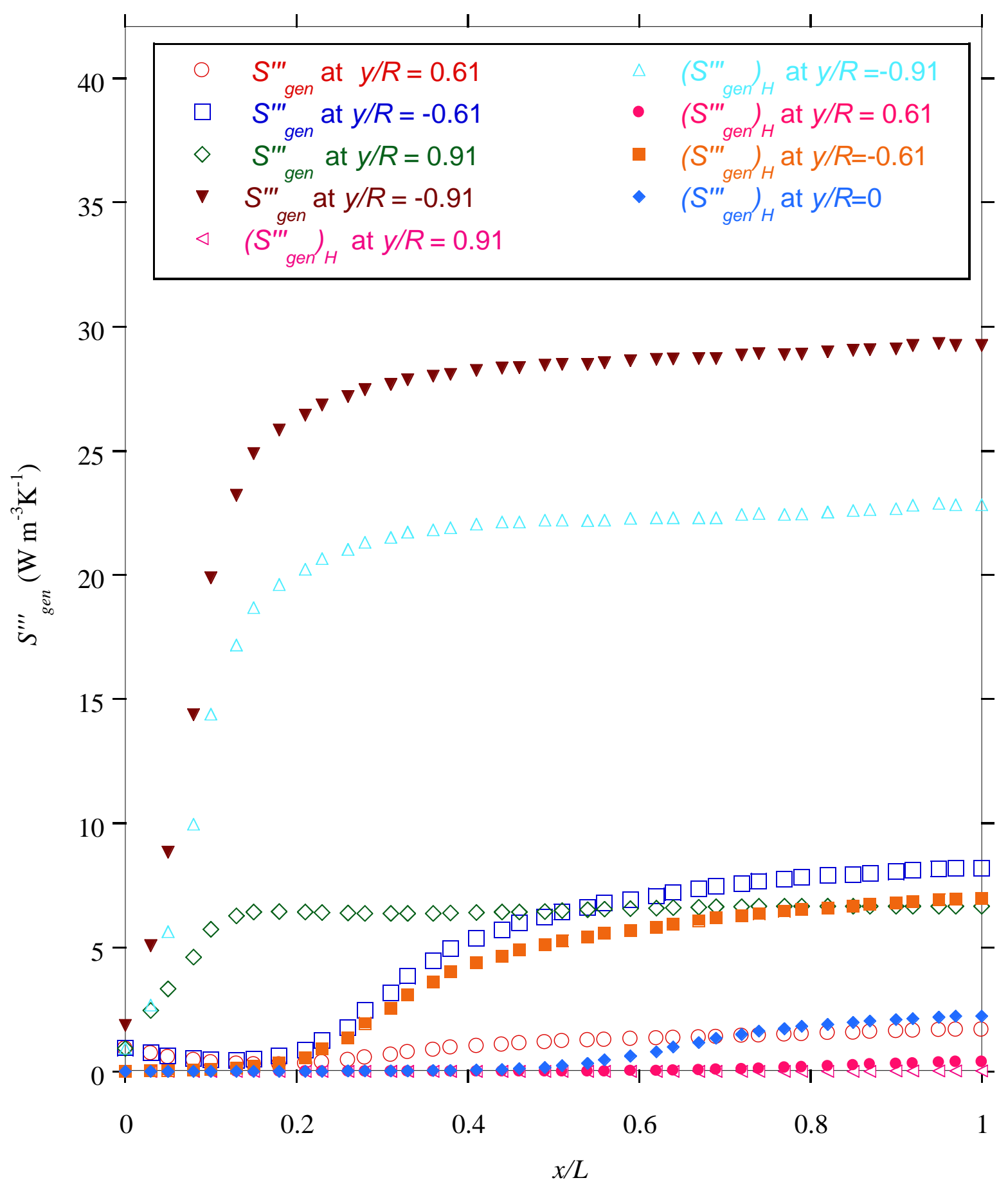

Fig. 8. Entropy generation at different values of $x / L$ 


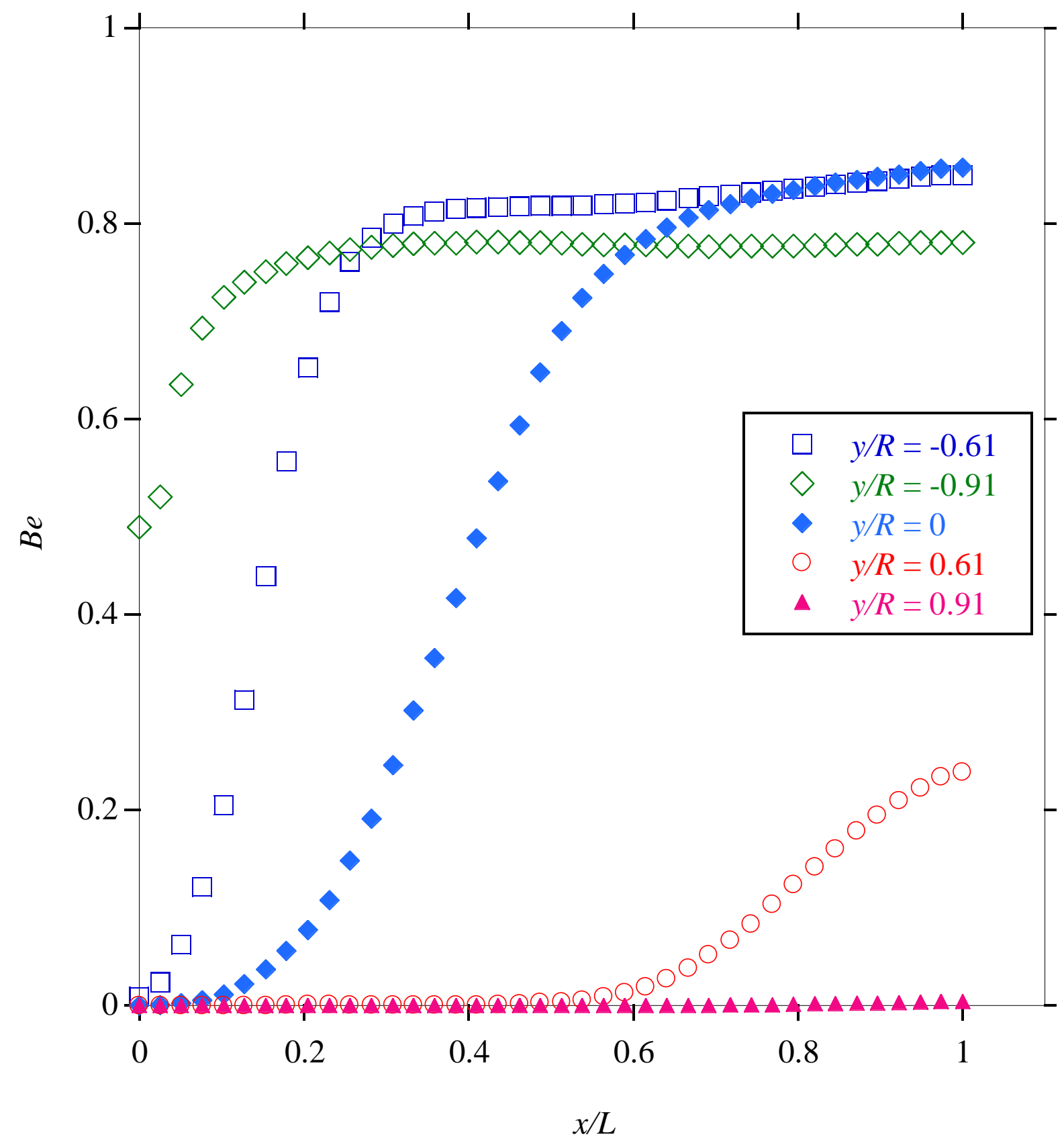

Fig. 9.Variation of Bejan number along the absorber tube's radial and axial directions

concentrated heat flux. At half the length of the absorber tube $(x / L=0.5)$, the entropy distribution shows a minimum at $y / R=0$ since the flow is still thermally developing, as the contribution of heat transfer irreversibility to total entropy generation are minimal. The entropy generation distribution at $x / L=0.75$ and 1 , shows a more constant profile for entropy generation rate given that, at these distances, flow is thermally fully developed.

Fig. 8 shows entropy generation at different values of $y / R$ along the length of the absorber tube, both $S^{\prime \prime \prime}{ }_{g e n}$ and $\left(S^{\prime \prime \prime}{ }_{\text {gen }}\right)_{H}$ are shown. $\left(S^{\prime \prime \prime}{ }_{g e n}\right)_{H}$ is the dominant source of irreversibility in the regions very close to the lower wall as shown at $y / R=-0.91$. The heat 
transfer irreversibility is high close to the absorber tube's lower wall because of the concentrated heat flux incident on the lower half of the absorber tube. Far from the lowerabsorber tube wall, the contribution of $\left(S^{\prime \prime \prime}{ }_{g e n}\right)_{H}$ to the total entropy generation rate reduces. For example, at $y / R=0.91$ (close to the upper-absorber tube wall), the contribution of $\left(S^{\prime \prime \prime}{ }_{\text {gen }}\right)_{H}$ to total entropy generation is just above zero and $S^{\prime \prime \prime}{ }_{\text {gen }}$ is $5 \mathrm{~W} \mathrm{~m}^{-3} \mathrm{~K}^{-1}$. Compared to the lower wall of the absorber tube, the upper wall receives only direct solar radiation, thus the observed lower values of heat transfer irreversibility. Fig. 9 shows the contribution of the total entropy generation which is due to heat transfer irreversibility in the absorber tube at various locations using the Bejan number. The Bejan number approaches 1 in the lower half of the absorber tube and is about zero close to the upper absorber tube wall.

\subsection{Effect of concentration ratio on entropy generation}

To investigate the effect of the concentration ratio on entropy generation, concentration ratios of 40,60, 80, 100 and 120 were considered. Since Reynolds numbers depend on the fluid inlet temperature and flow rates, for comparison purposes, the fluid's flow rate is used (where the flow rate, $\dot{V}=u_{\text {inlet }} \times A_{c}$ ). Two flow rates $\dot{V}=5.132 \times 10^{-3} \mathrm{~m}^{3} / \mathrm{s}$ (Fig. 10) and $\dot{V}=29.080 \times 10^{-3} \mathrm{~m}^{3} / \mathrm{s}$ (Fig. 11) were used to show the variation of entropy generation with inlet temperature and concentration ratio. Figs. 10-11 shows that at a given flow rate, the entropy generation rate per unit length $\left(S_{g e n}^{\prime}=S_{g e n} / L\right)$ reduces as the absorber tube inlet temperature increases. Furthermore, at a given flow rate and inlet temperature, the entropy generation increases as the concentration ratio increases. Increasing the concentration ratios means increased heat flux on the absorber tube, thus higher temperature gradients and increased heat transfer irreversibility, such that higher fluid flow rate or heat transfer augmentation is required for better heat transfer. The entropy generation rates at lower flow rates are higher as shown in Fig. 10 compared with entropy generation rates at high flow rates as shown in Fig. 11. As the flow rate increases, the heat transfer irreversibility is reduced but the fluid friction irreversibility increases. Both figures show a reduction in entropy generation as the heat transfer fluid inlet temperatures increase. The reduction in entropy generation as the inlet temperature increases is due to variation of the fluid's thermal properties with temperature, as the inlet temperatures increase, the fluid becomes less dense and less viscous thus leading to reduced fluid friction irreversibility. 


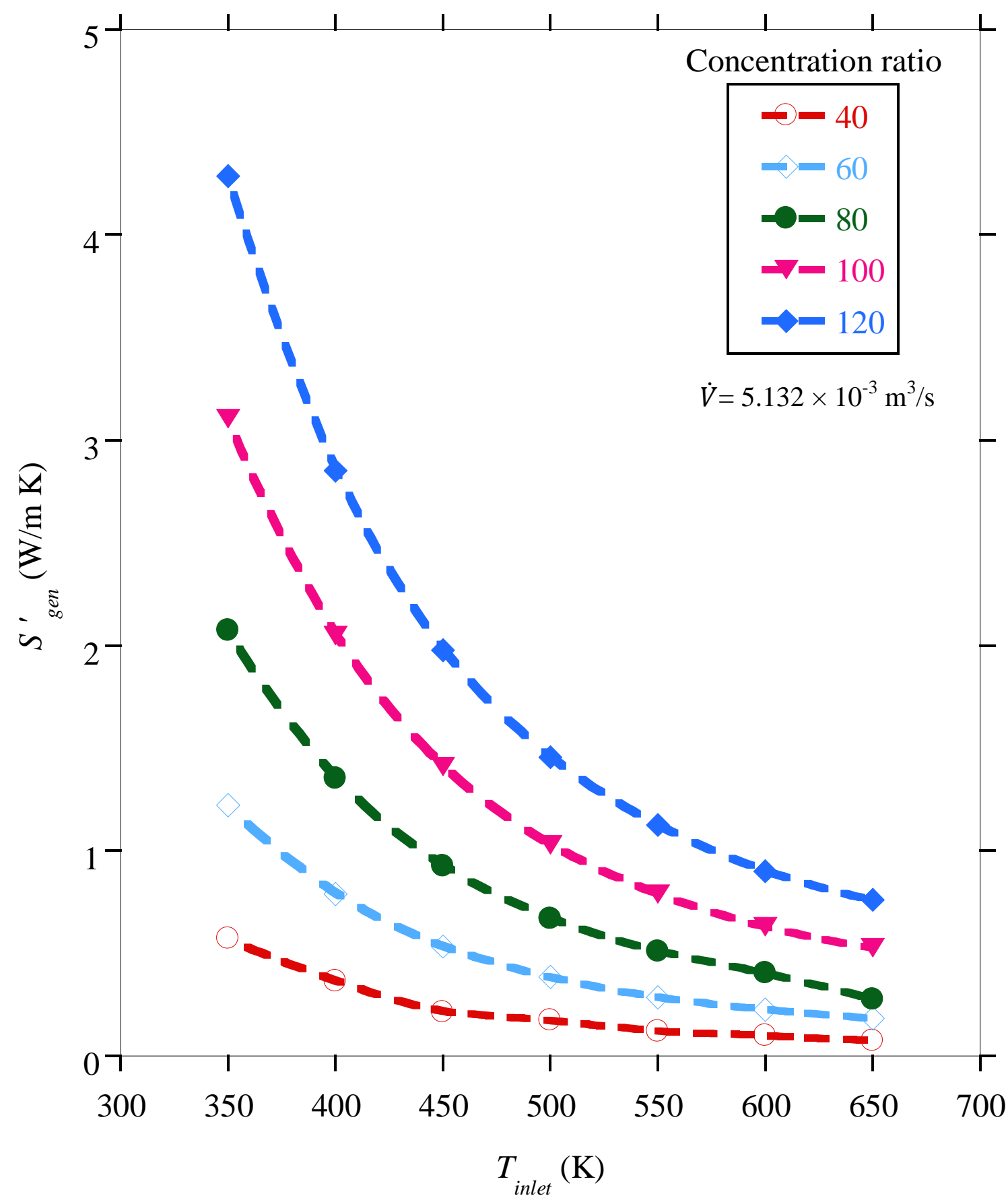

Fig. 10. Effect of concentration ratio on entropy generation at $\dot{V}=5.132 \times 10^{-3} \mathrm{~m}^{3} / \mathrm{s}$ 


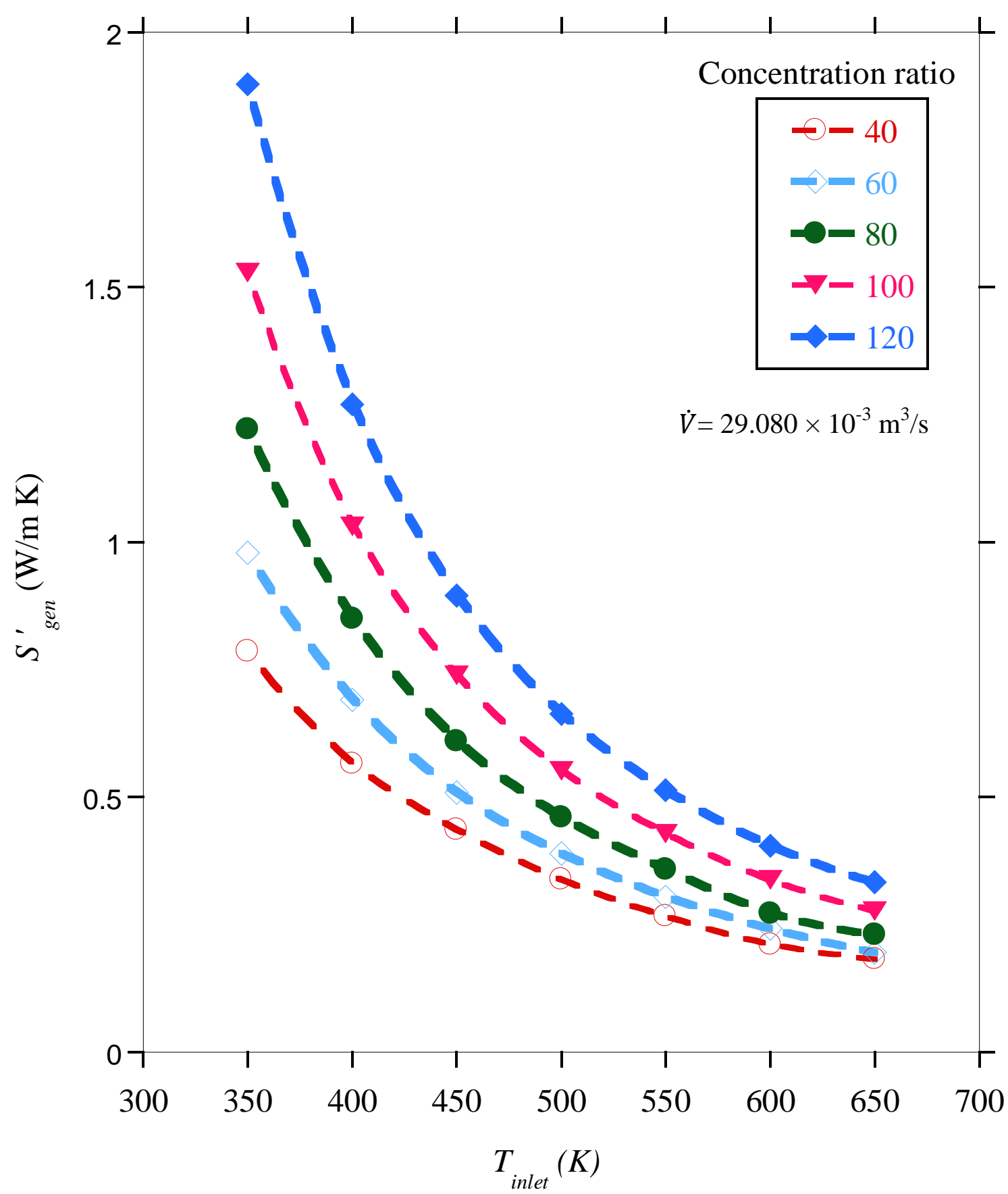

Fig. 11. Effect of concentration ratio on entropy generation at an inlet velocity of $\dot{V}=29.080 \times 10^{-3} \mathrm{~m}^{3} / \mathrm{s}$

To present results in terms of the Reynolds numbers, specific fluid inlet temperatures are considered. Figs. 12-13 show the Nusselt number and friction factor respectively for an inlet temperature of $550 \mathrm{~K}$, the figures show that increasing the concentration ratio has no effect on the Nusselt number and friction factor. They also show that increasing the Reynolds numbers continually increases the Nusselt numbers and reduces the friction factor. Thus based on the first law of thermodynamics there is no clear optimal operation point. However, analysis based on second law of thermodynamics shows that at a given concentration ratio, an 


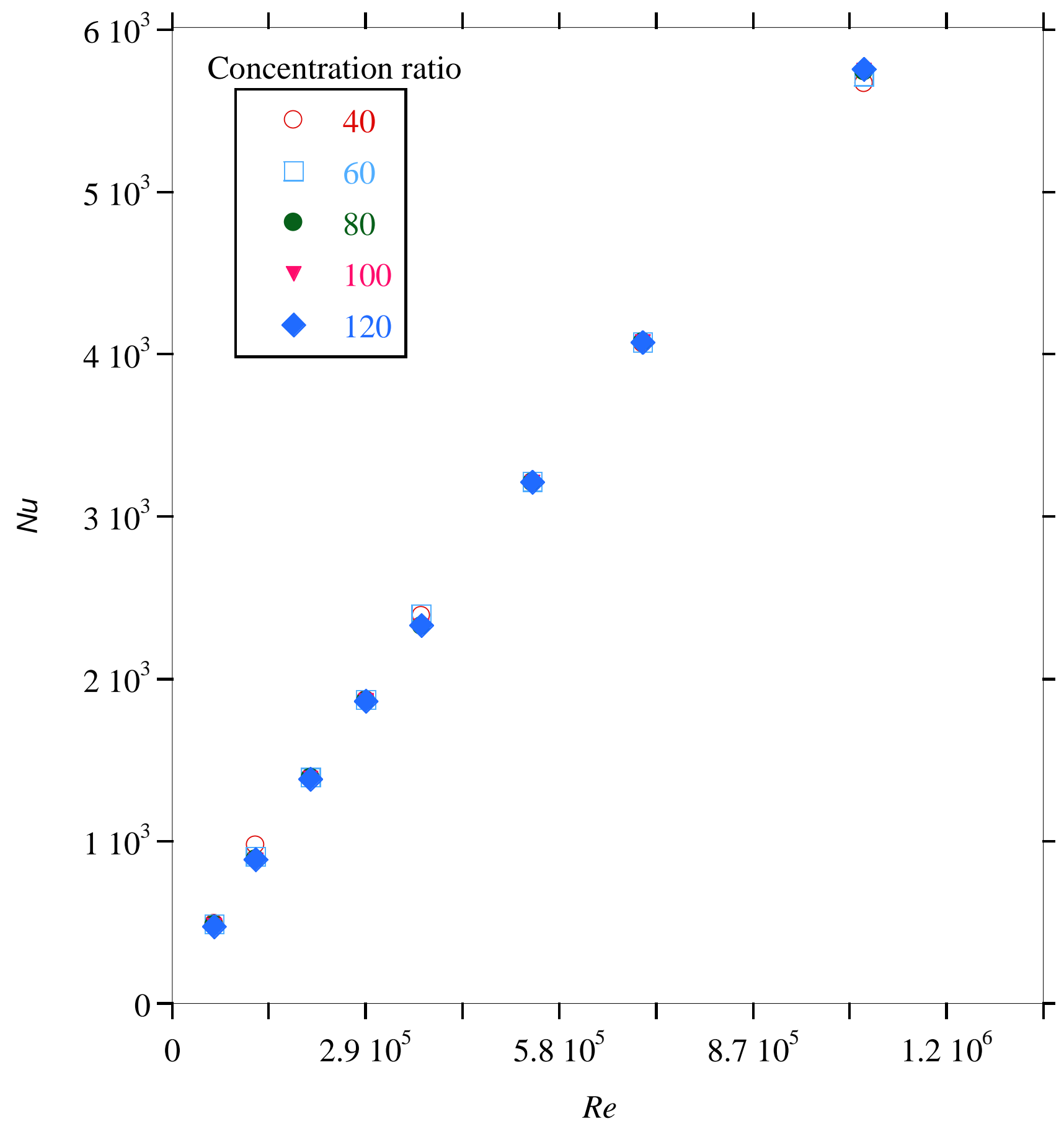

Fig. 12. Effect of concentration ratio on Nusselt number at $T_{\text {inlet }}=550 \mathrm{~K}$ 


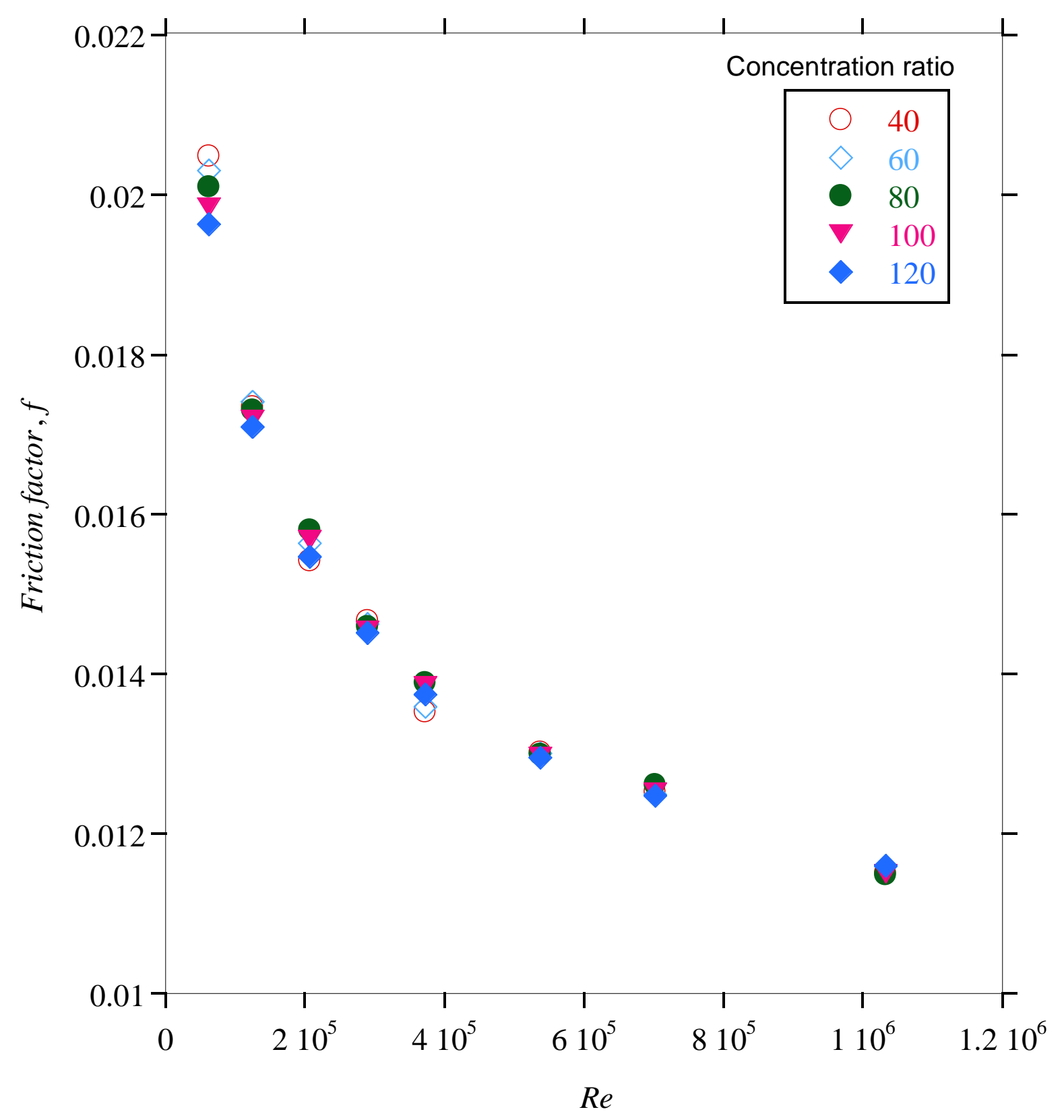

Fig. 13. Effect of concentration ratio on friction factor at $\boldsymbol{T}_{\text {inlet }}=550 \mathrm{~K}$

increase in the Reynolds number reduces the heat transfer irreversibility while increasing the fluid friction irreversibility. As such, there is a Reynolds number at which the sum of the heat transfer irreversibility and fluid friction irreversibility is a minimum. Figs. 14-15 show that for every concentration ratio and a given inlet temperature, there is some Reynolds number that minimises entropy generation in the absorber tube. The Figures also show that high concentration ratios result in higher entropy generation rates due to increased heat transfer irreversibility. The optimum Reynolds number is shown to increases as the concentration 


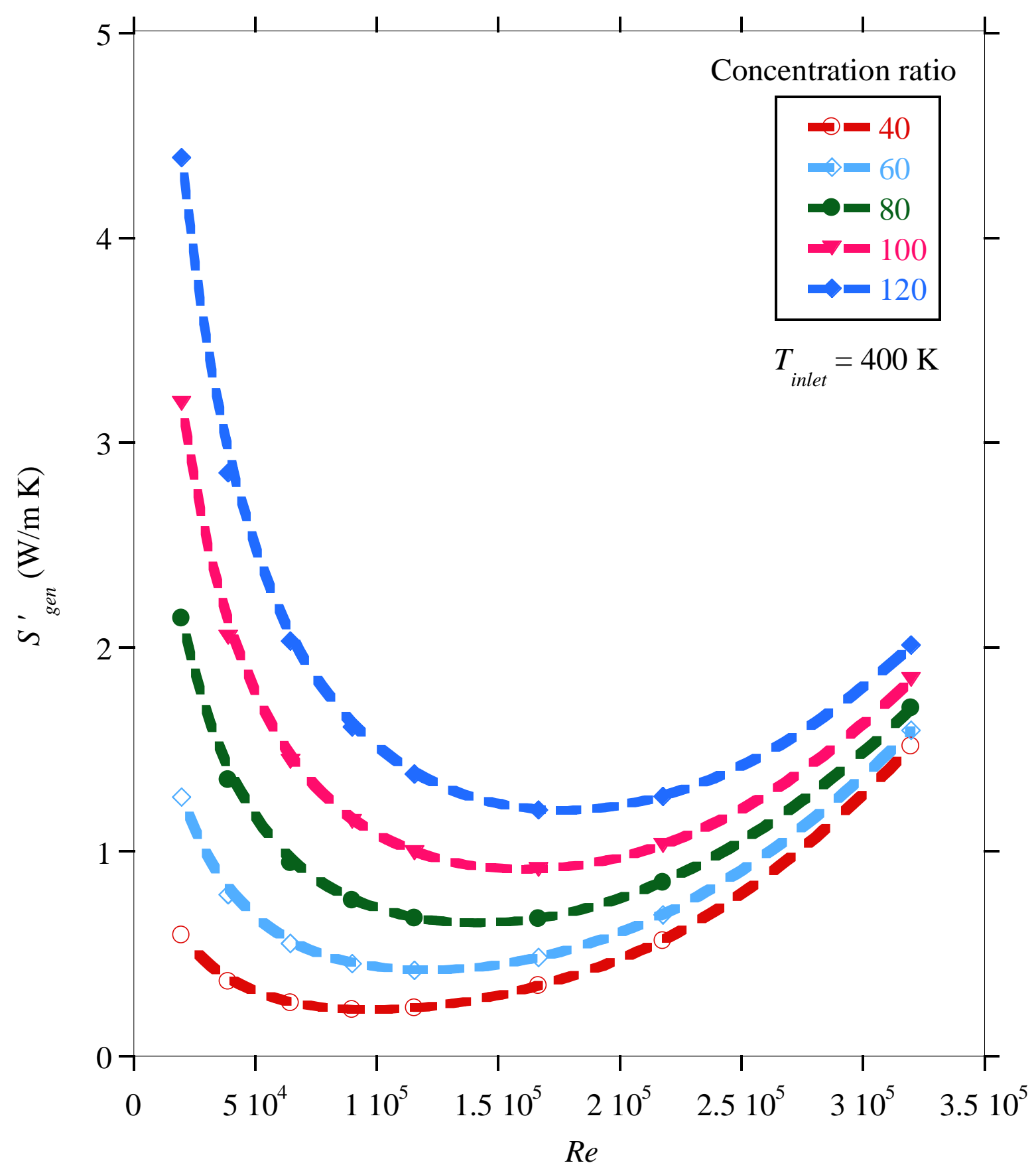

Fig. 14. Effect of concentration ratio on entropy generation at different Reynolds numbers $\left(T_{\text {inlet }}=400 \mathrm{~K}\right)$ 


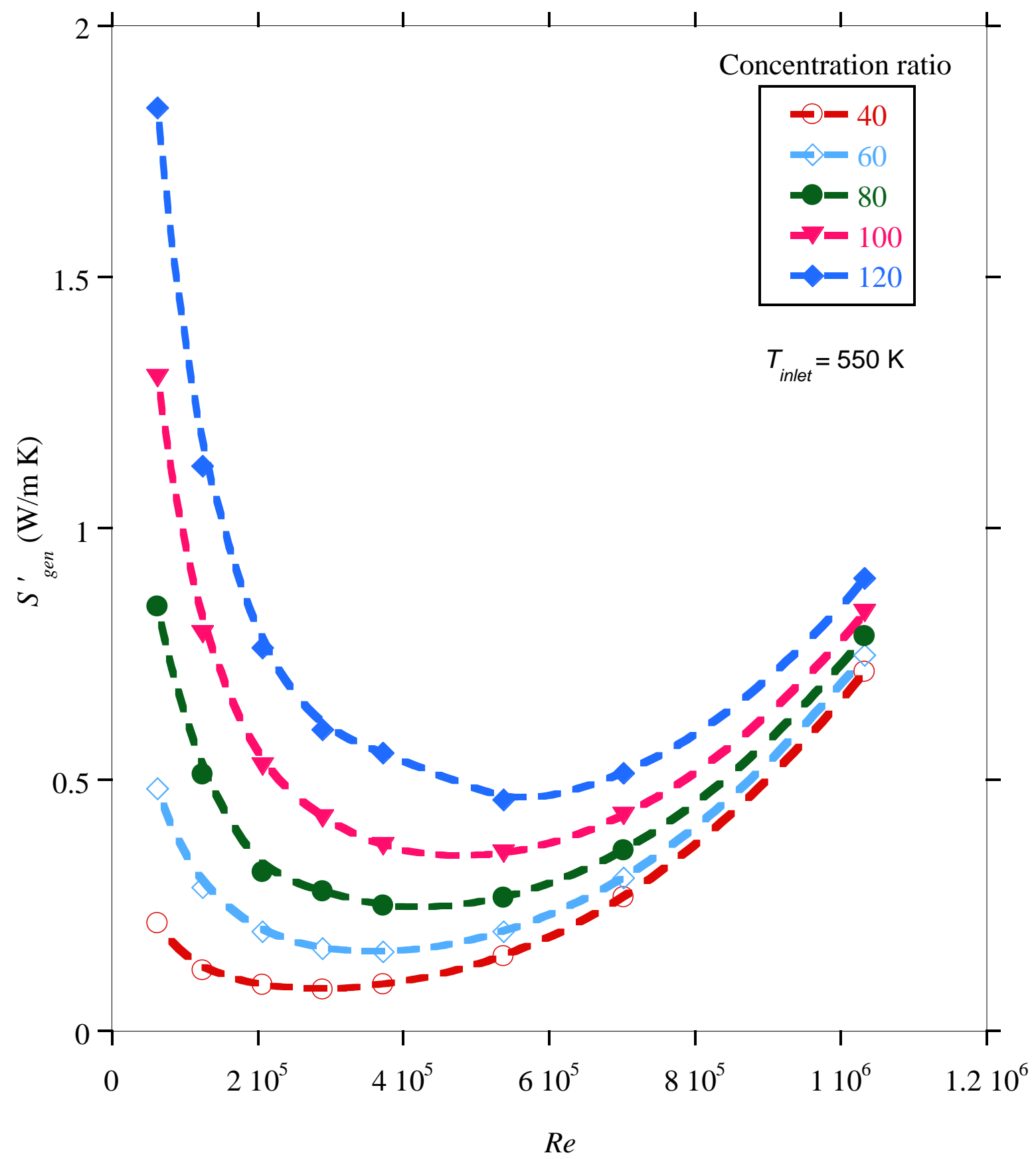

Fig. 15. Effect of concentration ratio on entropy generation at different Reynolds numbers $\left(T_{\text {inlet }}=550 \mathrm{~K}\right)$ 


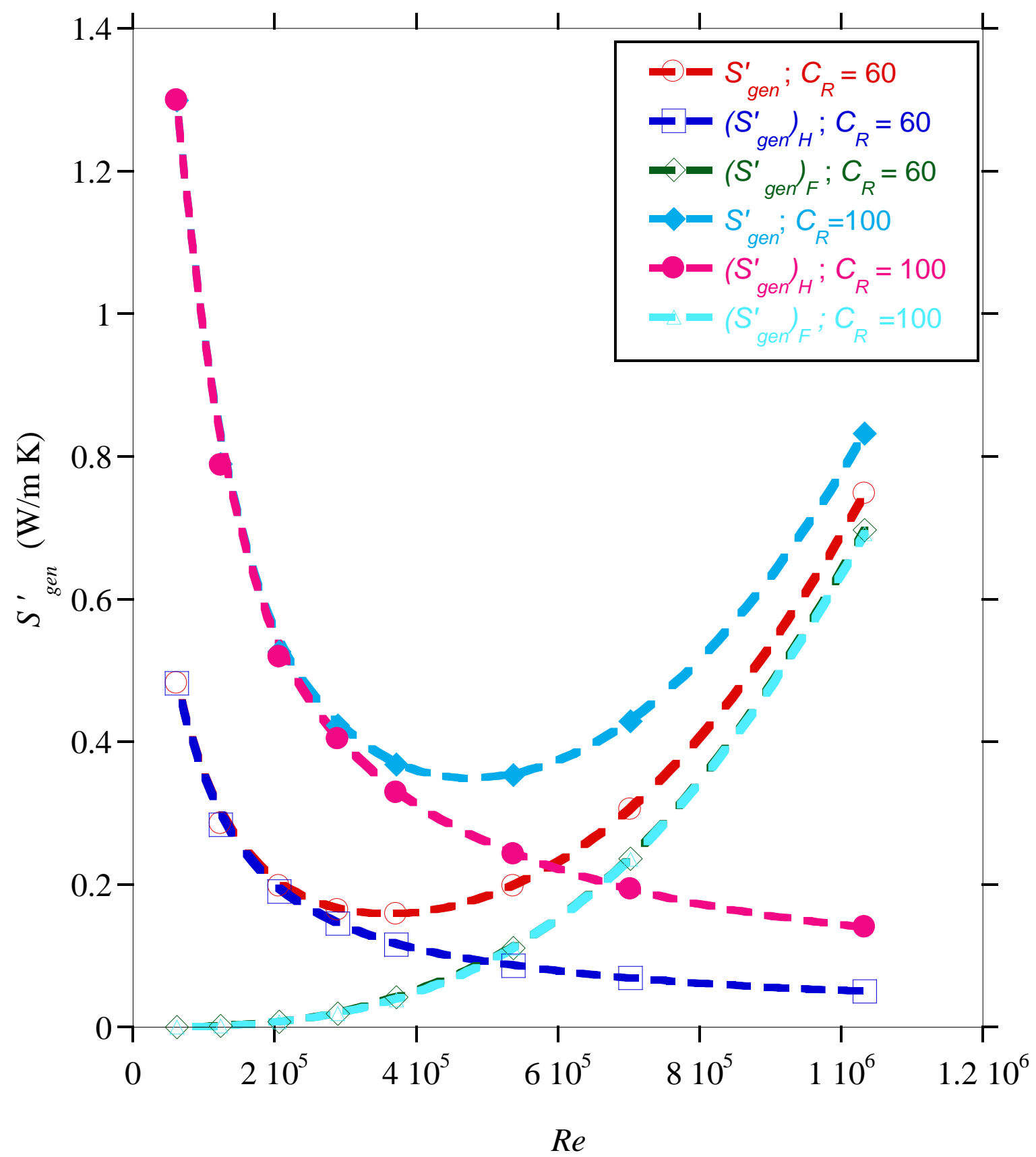

Fig. 16. Effect of concentration ratio on entropy generation distribution at different Reynolds numbers $\left(T_{\text {inlet }}=550 \mathrm{~K}\right)$

ratio increases, therefore, an increase in concentration ratio would require a corresponding increase in heat transfer fluid flow rate to minimize the heat transfer irreversibility for minimum entropy generation.

Fig. 16 shows the distribution of entropy generation at concentration ratios of 60 and 100 at $T_{\text {inlet }}=550 \mathrm{~K}$. The fluid friction irreversibility increases with an increase in Reynolds number but does not change with changing concentration ratio, whereas the heat transfer irreversibility decreases with increasing Reynolds numbers and increases significantly as the 


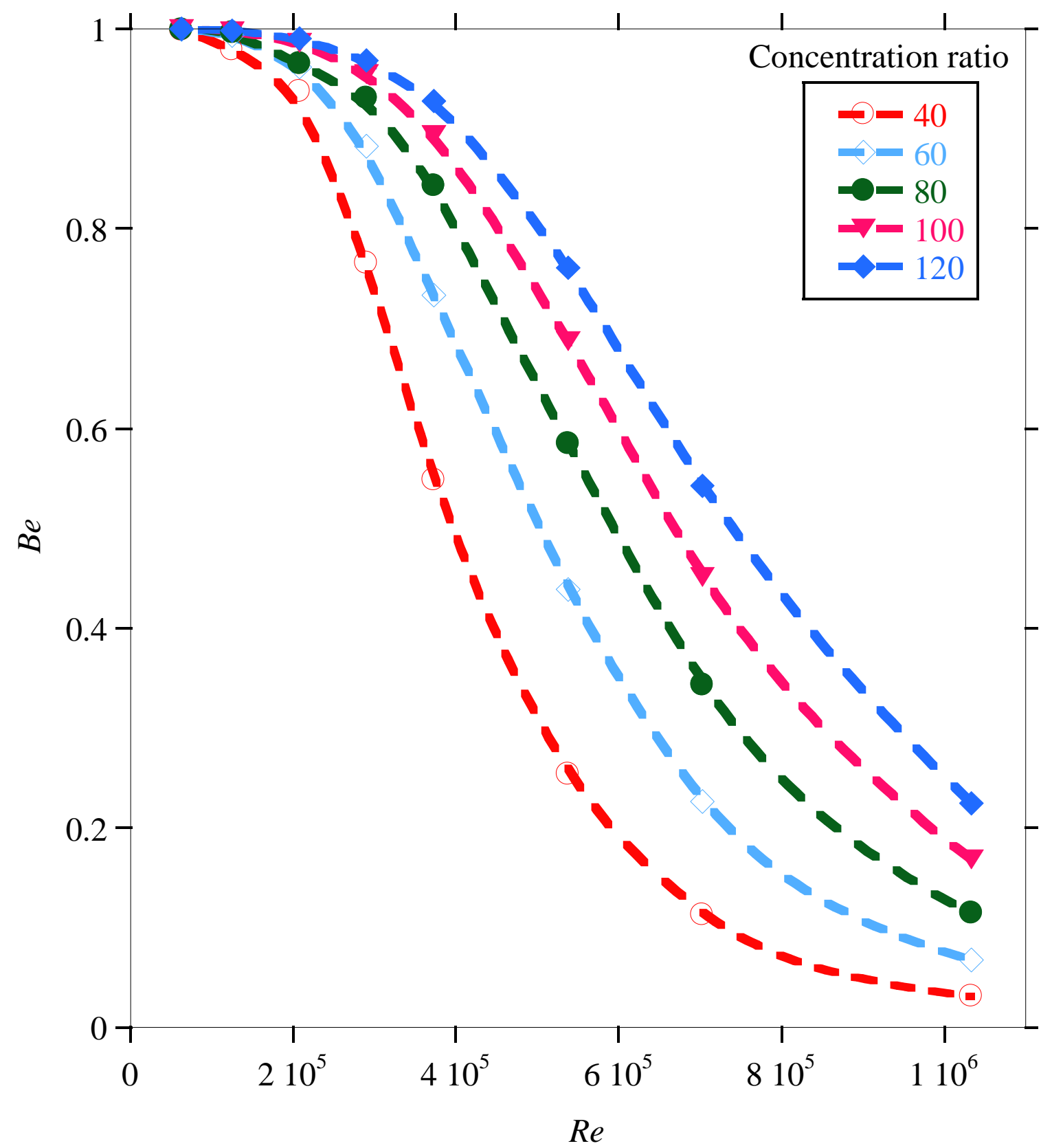

Fig. 17. Variation of Bejan number with Reynolds number and concentration Ratio $\left(T_{\text {inlet }}=550 \mathrm{~K}\right)$

concentration ratios increase. The entropy generation due to heat transfer is dominant at low Reynolds numbers because of the low heat transfer coefficients and entropy generation due to fluid friction becomes the dominant source at high values of Reynolds number because of the increased pressure drop. For all concentration ratios, Fig. 17 shows the variation of the Bejan number with concentration ratio and the Reynolds number at $T_{\text {inlet }}=550 \mathrm{~K}$. The Bejan number approaches 1 at very low Reynolds numbers and approaches zero as Reynolds numbers are increased for low concentration ratios. The Bejan number is also shown to increase with increase in concentration ratios. 


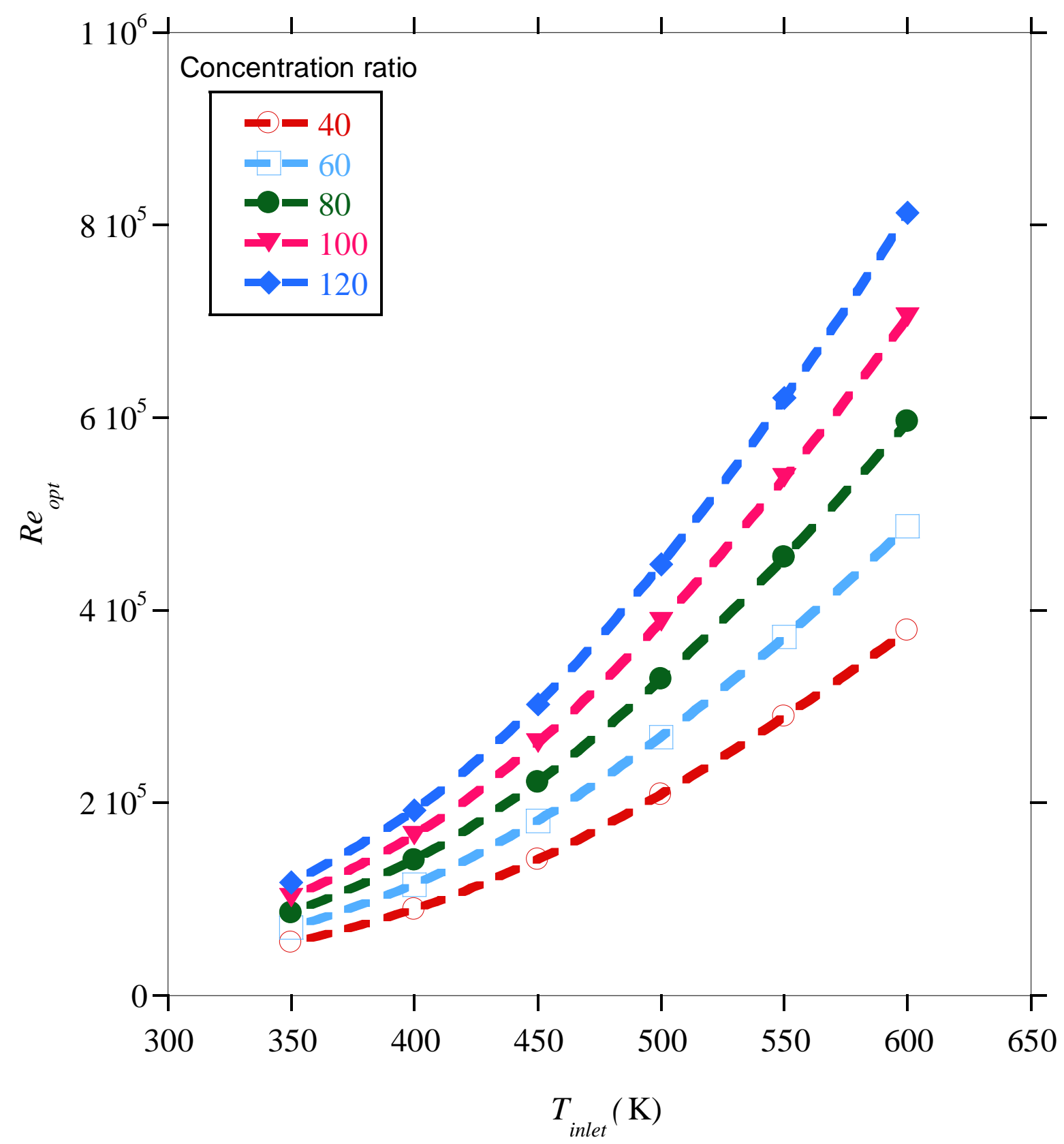

Fig. 18. Variation of optimal Reynolds number with concentration ratio and inlet temperature

The optimal Reynolds number (at which entropy generation is a minimum) is shown to increase as the concentration ratio increases, as shown in Figs.14, 15 and 18 for specific inlet temperatures. Fig.18 also shows that as the inlet temperatures increase, the optimal Reynolds number also increases. This is because the density and viscosity of the fluid were taken to vary with temperature. Based on heat transfer fluid flow rate, the flow rates corresponding to the optimal Reynolds number are the same for the different inlet temperatures at a given concentration ratio. For all inlet temperatures, the optimal flow rates 


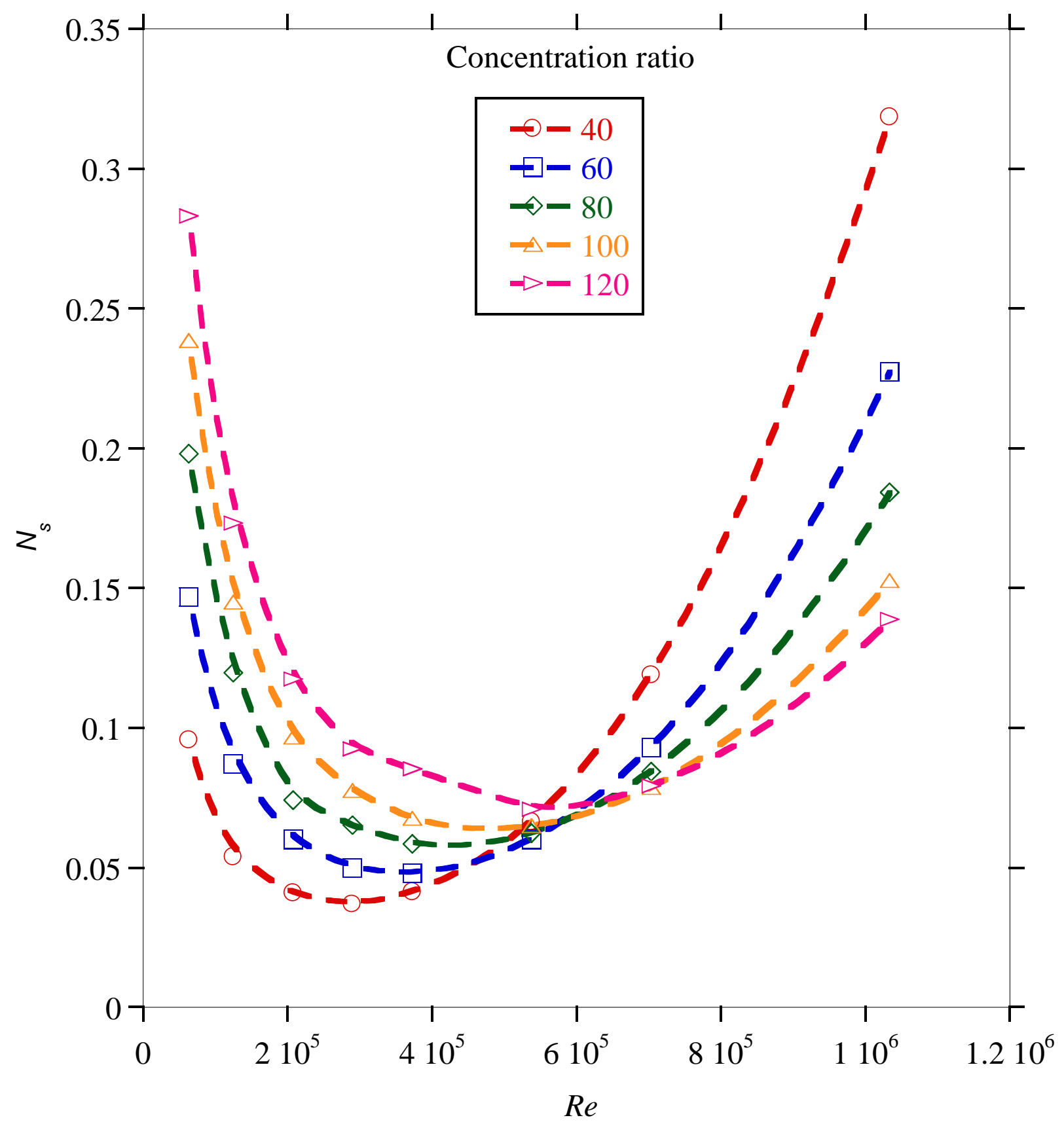

Fig. 19. Variation of entropy generation number with Reynolds number and concentration ratio at $T_{\text {inlet }}=$ $550 \mathrm{~K}$

are $11.974 \times 10^{-3}, 15.395 \times 10^{-3}, 18.817 \times 10^{-3}$, and $22.238 \times 10^{-3}$ and $25.659 \times 10^{-3} \mathrm{~m}^{3} / \mathrm{s}$ at concentration ratios $40,60,80,100$ and 120 respectively.

For fair evaluation of entropy generation at different concentration ratios, the nondimensional entropy generation number $N_{s}$, which relates the entropy generated to the inlet temperature and heat transfer rate was defined as;

$N_{s}=\frac{S_{g e n}}{\dot{q} / T_{\text {inlet }}}$, where $\dot{q}$ - is the heat transfer rate and $T_{\text {inlet }}$ - is the inlet temperature. 
Fig. 19 shows the variation of $\mathrm{N}_{\mathrm{s}}$ with Reynolds number at an inlet temperature of 550 $\mathrm{K}$. The location of the optimal Reynolds number is clearly shown and does not differ from that obtained in Figs. 14 and 15. However, Fig. 19 shows that the entropy generation number is higher as the concentration ratios increase for low Reynolds numbers and becomes lower as the concentration ratios increase for higher flow rates. Therefore, for lower concentration ratios, higher flow rates are undesirable.

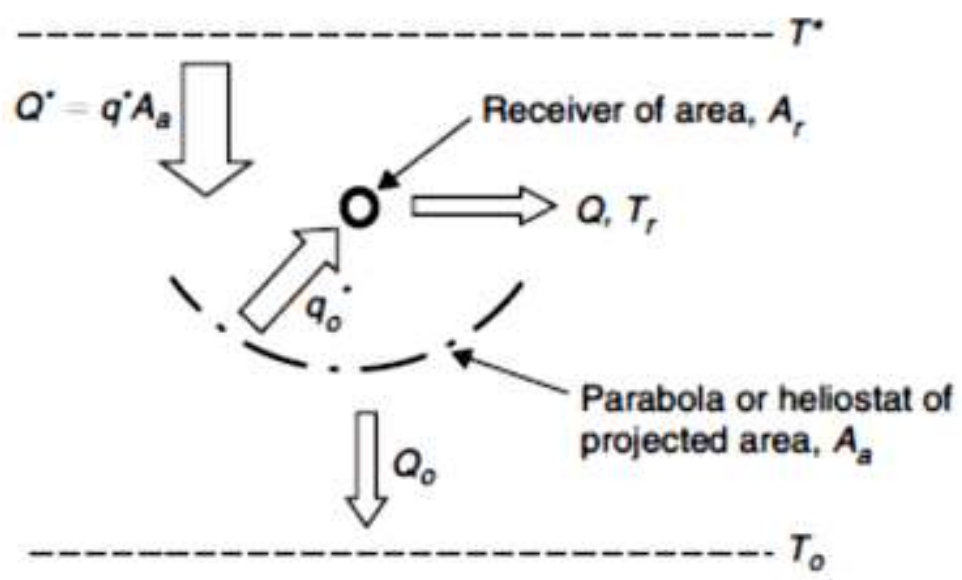

(a)

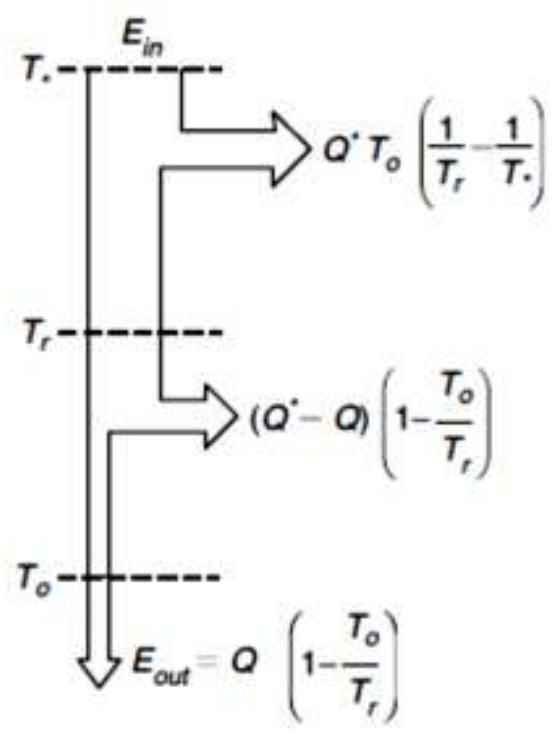

(b)

Fig. 20. (a). Imaging collector model (b). Exergy flow diagram in the collector [1] 


\subsection{Comparison with entropy generation for the entire collector system}

Thus far, we have presented results of entropy generation due to heat transfer and fluid flow in the parabolic trough receiver alone. To compare with the entropy generation for the entire collector system, the method proposed by Bejan[23] for solar collectors is used. The method considers entropy generation upstream of the collector, downstream of the collector and inside the collector. The exergy flow diagram is shown in Fig. 20 [1] for a collector of area $A_{a}$, receiving solar radiation at a rate $Q^{*}$ from the sun. $Q^{*}$ is proportional to the area of the collector and the direct normal irradiance, $I_{b}$. The incident solar radiation is partly delivered to the user as heat transfer $Q$ at the receiver temperature $T_{r}$, the remaining fraction, $Q_{o}$ is lost to the ambient. The entropy generation due to these processes for a nonisothermal collector without considering the pressure drop between the inlet and outlet is given as $[1,23]$.

$S_{\text {gen }, c o l}=\dot{m} c_{p} \ln \frac{T_{\text {out }}}{T_{\text {inlet }}}-\frac{Q^{*}}{T_{*}}+\frac{Q_{o}}{T_{o}}$

Where $T *$ is the apparent temperature of the sun as an energy source approximately equal to $3 / 4 T_{s}[1], T_{s}$ is the apparent blackbody temperature of the sun, $T_{o}$ is the ambient temperature, $Q_{o}=Q^{*}-Q$ and $Q=\dot{m} c_{p}\left(T_{\text {out }}-T_{\text {in }}\right)$.

Fig. 21 shows the entropy generation rate per unit length $\left(S_{\text {gen,col }}^{\prime}=S_{\text {gen,col }} / L\right)$ of the entire collector system at $T_{\text {inlet }}=400 \mathrm{~K}$ at different concentration ratios and Reynolds numbers. The figure shows that, the entropy generation rate of the collector system is strongly dependent on the concentration ratio than on Reynolds numbers. This is due to the increase in the entropy generation from heat transfer as concentration ratios increase. A closer look at each concentration ratio shows that the entropy generation is minimum at some Reynolds number as shown in Fig.22 for $C_{R}=80$. This is in agreement with our analysis when only entropy generation due to heat transfer and fluid friction was considered. Therefore, the entropy generation due to heat transfer and fluid friction in the receiver is somehow related to the collector's entropy generation through the first term in Eq. 30. The point of minimum entropy will exist in this case due to the fact that the mass flow rate and outlet temperature in the first term of Eq.30 are interdependent. Increasing the mass flow rate increases the contribution due to $\dot{m} c_{p}$ while at the same time reducing the contribution due to $\ln \left(T_{\text {out }} / T_{\text {inlet }}\right)$, such that there is a point at which the product of the two terms is minimum. Table 3.0 provides a summary of the entropy generation from the different processes given in 


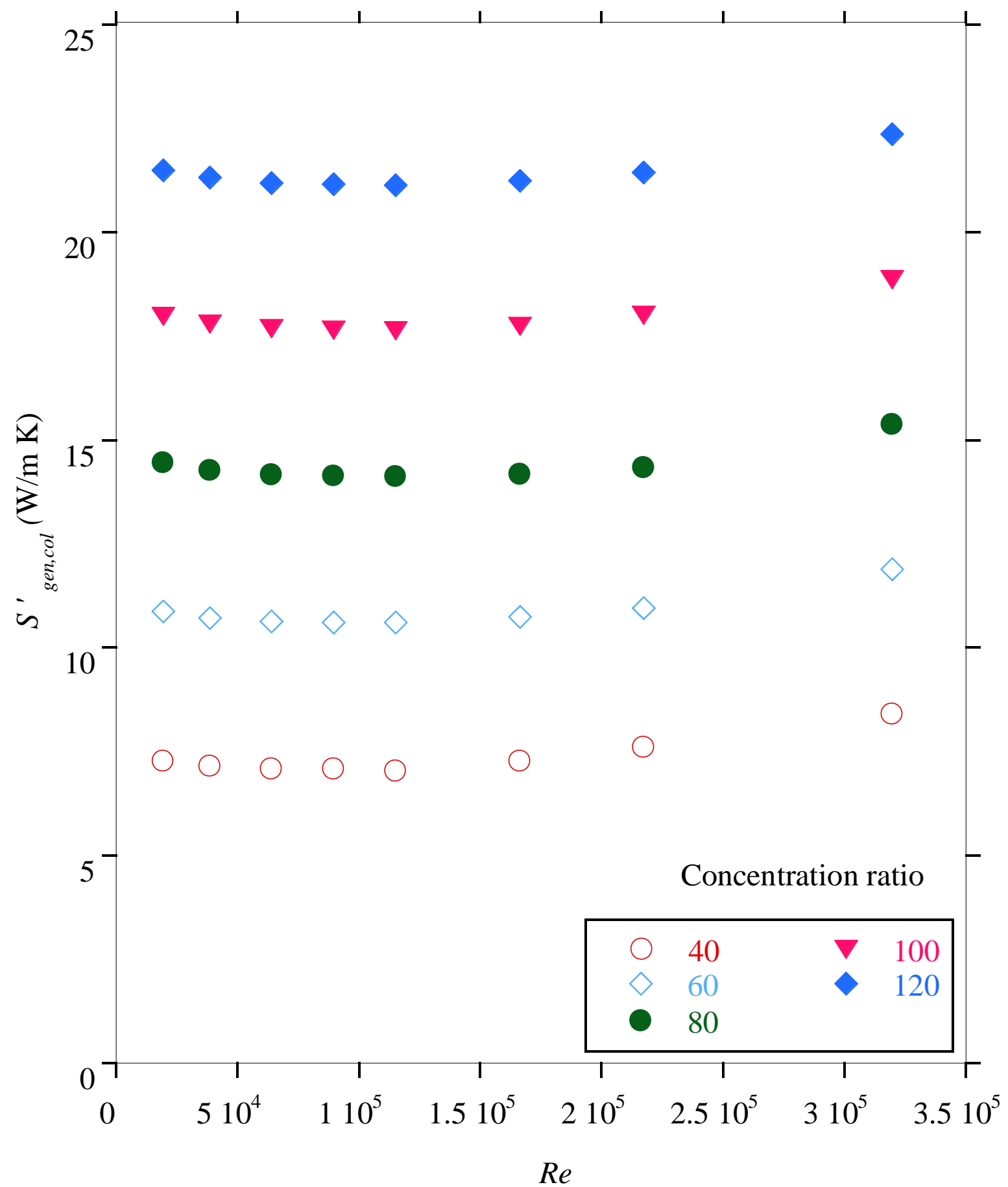

Fig. 21. Entropy generation for an entire collector system at different Reynolds numbers and concentration ratios at $T_{\text {inlet }}=400 \mathrm{~K}$ 


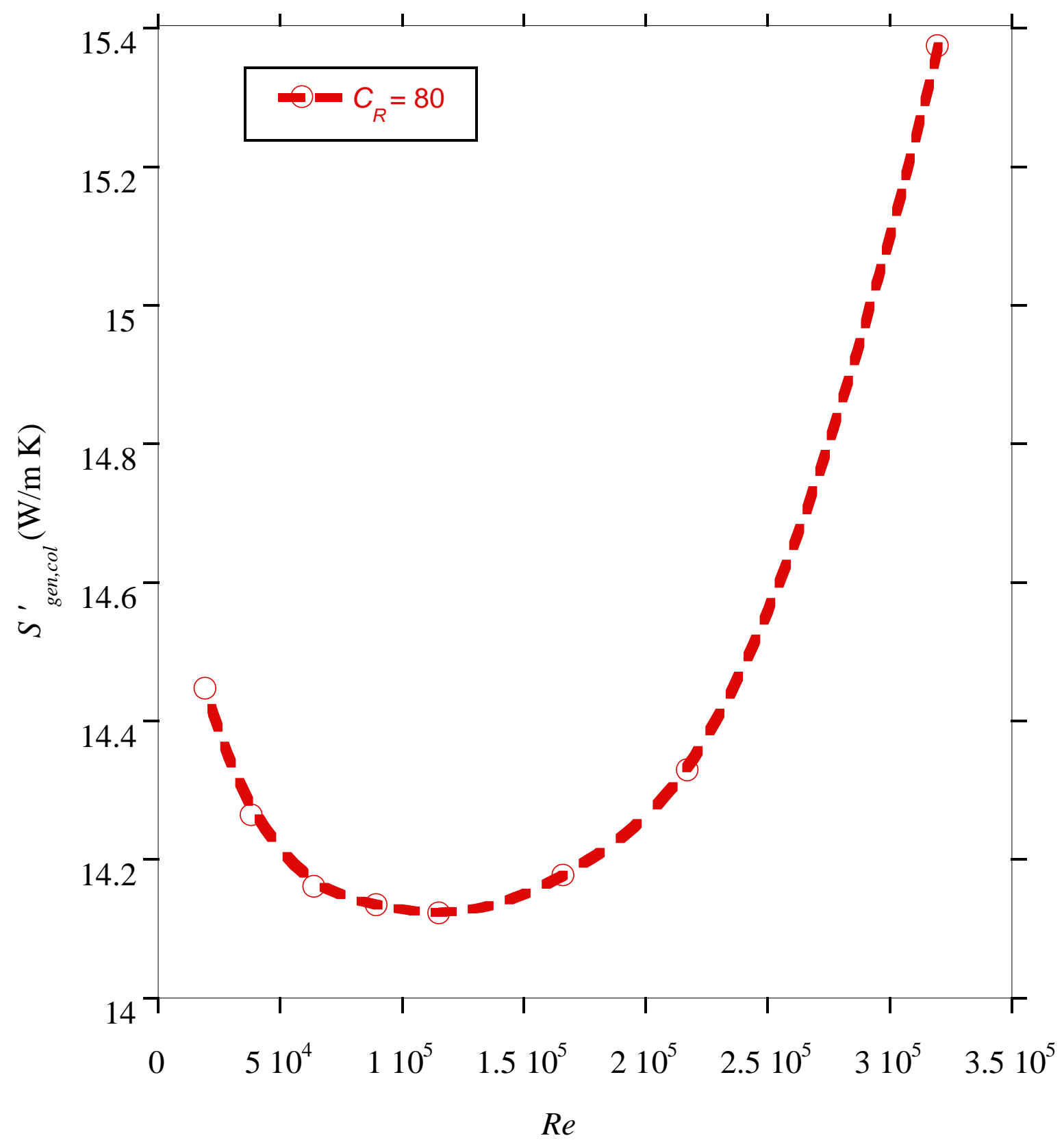

Fig. 22. Entropy generation per meter of the parabolic trough collector at $C_{R}=80, T_{\text {inlet }}=400 \mathrm{~K}$

Eq.30 and a comparison with the entropy generation due to heat transfer and fluid flow as determined by the CFD analysis. 
Table 3.0: Entropy generation due to heat transfer and fluid flow compared with entropy generation in the collector

\begin{tabular}{|c|c|c|c|c|c|c|}
\hline \multicolumn{7}{|c|}{$T_{\text {inlet }}=400 \mathrm{~K}, C_{R}=80$} \\
\hline $\begin{array}{c}\text { Flow rate } \\
\left(\mathrm{m}^{3} / \mathrm{s}\right) \times 10^{-3}\end{array}$ & $\begin{array}{r}\dot{m} c_{p} \ln \frac{T_{\text {out }}}{T_{\text {in }}} \\
(\mathrm{W} / \mathrm{K})\end{array}$ & $\begin{array}{l}Q^{*} / T_{*} \\
(\mathrm{~W} / \mathrm{K})\end{array}$ & $\begin{array}{l}Q_{\delta} / T_{o} \\
(\mathrm{~W} / \mathrm{K})\end{array}$ & $\begin{array}{c}S_{\text {gen,col }}^{\prime} \\
(\mathrm{W} / \mathrm{m} \mathrm{K})\end{array}$ & $\begin{array}{c}S_{\text {gen }}^{\prime} \\
(\mathrm{W} / \mathrm{m} \mathrm{K})\end{array}$ & $\begin{array}{l}S_{g e n}^{\prime} / S_{g e}^{\prime} \\
n, \operatorname{col}(\%)\end{array}$ \\
\hline 2.566 & 52.464 & 5.173 & 10.495 & 14.447 & 2.142 & 14.83 \\
\hline 5.132 & 51.947 & 5.173 & 10.279 & 14.263 & 1.352 & 9.48 \\
\hline 8.553 & 51.618 & 5.173 & 10.200 & 14.161 & 0.948 & 6.69 \\
\hline 11.974 & 51.527 & 5.173 & 10.182 & 14.134 & 0.762 & 5.39 \\
\hline 15.395 & 51.498 & 5.173 & 10.162 & 14.122 & 0.675 & 4.78 \\
\hline 22.238 & 51.801 & 5.173 & 10.080 & 14.177 & 0.673 & 4.75 \\
\hline 29.080 & 52.426 & 5.173 & 10.062 & 14.329 & 0.851 & 5.94 \\
\hline 42.765 & 56.718 & 5.173 & 9.950 & 15.374 & 1.703 & 11.08 \\
\hline \multicolumn{7}{|c|}{$T_{\text {inlet }}=550 \mathrm{~K}, C_{R}=80$} \\
\hline $\begin{array}{c}\text { Flow rate } \\
\left(\mathrm{m}^{3} / \mathrm{s}\right) \times 10^{-3}\end{array}$ & $\begin{array}{r}\dot{m} c_{p} \ln \frac{T_{\text {out }}}{T_{\text {in }}} \\
(\mathrm{W} / \mathrm{K})\end{array}$ & $\begin{array}{l}Q^{*} / T * \\
(\mathrm{~W} / \mathrm{K})\end{array}$ & $\begin{array}{l}Q_{o} / T_{o} \\
(\mathrm{~W} / \mathrm{K})\end{array}$ & $\begin{array}{l}S_{\text {gen,col }}^{\prime} \\
(\mathrm{W} / \mathrm{K})\end{array}$ & $\begin{array}{c}S_{\text {gen }}^{\prime} \\
(\mathrm{W} / \mathrm{K})\end{array}$ & $\begin{array}{c}\mathrm{S}_{\mathrm{gen}}^{\prime} / \mathrm{S}_{\mathrm{ge}}^{\prime} \\
\mathrm{n}, \mathrm{col}\end{array}$ \\
\hline 2.566 & 35.650 & 5.173 & 12.743 & 10.805 & 0.845 & 7.82 \\
\hline 5.132 & 35.101 & 5.173 & 12.326 & 10.563 & 0.510 & 4.83 \\
\hline 8.553 & 34.495 & 5.173 & 12.208 & 10.382 & 0.316 & 3.05 \\
\hline 11.974 & 34.502 & 5.173 & 12.150 & 10.370 & 0.278 & 2.68 \\
\hline 15.395 & 35.001 & 5.173 & 12.050 & 10.469 & 0.250 & 2.38 \\
\hline 22.238 & 35.800 & 5.173 & 11.902 & 10.632 & 0.266 & 2.50 \\
\hline 29.080 & 36.647 & 5.173 & 11.801 & 10.819 & 0.359 & 3.32 \\
\hline 42.765 & 38.344 & 5.173 & 11.699 & 11.218 & 0.785 & 7.00 \\
\hline
\end{tabular}

Given the assumed constant value of the direct normal irradiance $\left(I_{b}\right)$, the entropy generation from solar radiation $\left(Q^{*} / T_{*}\right)$ remains constant at a given concentration ratio. The entropy generation due to heat transfer $\left(\dot{m} c_{p} \ln \left(T_{\text {out }} / T_{\text {inlet }}\right)\right)$ is the largest contributor to the entropy generation budget of the collector system as seen in Table 3.0. For our analysis (4 m long collector system) a slight variation of the entropy generation due to heat transfer is noted at each inlet temperature and concentration ratio. This is because at a given inlet temperature and concentration ratio the heat transfer rate does not very so much over the $4 \mathrm{~m}$ long collector system considered. The entropy generation due to heat losses $\left(Q_{o} / T_{o}\right)$ reduces with increase in flow rates due to the reduced heat losses $\left(Q_{o}\right)$ resulting from the reduced temperature difference between the receiver and the surroundings.

The entropy generation due to heat transfer and fluid flow is a small percentage of the entropy generation for the entire collector system given by Eq.30. The percentage depends on the inlet temperature and the flow rate; $S_{\text {gen }}^{\prime}$ is about $14.83 \%$ of $S_{\text {gen },{ }^{\prime} \text { al }}$ at $T_{\text {inlet }}=400 \mathrm{~K}, C_{R}=$ 
80 when the flow rate is $2.566 \times 10^{-3} \mathrm{~m}^{3} / \mathrm{s}$ and $7.82 \%$ of $S_{\text {gen }}^{\prime}$ col when the inlet temperature is $550 \mathrm{~K}$ at the same flow rate and concentration ratio. Even though the entropy generation predicted for the entire collector system is large compared to the entropy generation due to heat transfer and fluid flow, they all show the same variation with temperature, concentration ratio and Reynolds number. Either of the two methods can be used to optimize performance of solar collector systems since it has been shown in this study that minimising entropy generation due to heat transfer and fluid flow minimises entropy generation for the entire collector system and vice versa.

\subsection{Conclusion}

A numerical analysis of entropy generation in a parabolic trough collector's solar receiver was carried out for different concentration ratios, inlet temperatures and Reynolds numbers. A comparison of the direct and the indirect methods of entropy generation shows that the results vary greatly since the receiver's absorber tube is subject to concentrated solar flux on the lower half and direct solar irradiation on the upper half. Even though, the analysis based on the first law of thermodynamics shows no variation in the Nusselt number and friction factor as concentration ratios change, using the second law of thermodynamics shows that increasing concentration ratios increases the entropy generation rates in the receiver.

For a given inlet temperature, it has been shown using the Bejan number, that entropy generation due to heat transfer dominates for lower values of Reynolds number, whereas entropy generation due to fluid friction dominates for higher values of Reynolds number. The Bejan number approaches 1 for $R e<2 \times 10^{5}$ for all the concentration ratios and is less than 0.4 for $R e>8 \times 10^{5}$ for all concentration ratios when $T_{\text {inlet }}=550 \mathrm{~K}$. The Bejan number also increases as the concentration ratio increases for a given inlet temperature and Reynolds number.

It was also shown that at a given concentration ratio and inlet temperature, there is a Reynolds number $\left(R e_{\text {opt }}\right)$ for which the entropy generation is a minimum. The value of the optimum Reynolds number increases as the concentration ratio increases. Because of the variation of the fluid's heat transfer properties, the optimal Reynolds number is shown to increase as the inlet temperature increases, however, the obtained optimal Reynolds numbers correspond to volumetric flow rates of $11.974 \times 10^{-3}, 15.395 \times 10^{-3}, 18.817 \times 10^{-3}$, and 22.238 $\times 10^{-3}$ and $25.659 \times 10^{-3} \mathrm{~m}^{3} / \mathrm{s}$ when the concentration ratios are 40,60, 80, 100, and 120 respectively regardless of the inlet temperature used. It has also been shown that minimising 
the entropy generation due to heat transfer and fluid flow in the receiver minimises the entropy generation for the entire collector system.

\subsection{Acknowledgement}

The authors acknowledge the support received from the Department of Mechanical and Aeronautical Engineering, University of Pretoria, Pretoria, South Africa.

\section{REFERENCES}

[1] Kalogirou S. Solar energy engineering: processes and systems. $1^{\text {st }}$ ed. Oxford U.K.: Elsevier; 2009.

[2] Duffie John A, Beckman William A. Solar engineering of thermal processes. $3^{\text {rd }}$ ed. Hoboken New Jersey: John Wiley and Sons Inc.; 2006.

[3] Price H, Lupfert E, Kearney D, Zarza E, Cohen G, Gee R, Mahoney R. Advances in parabolic trough solar power technology. ASME J Solar Energy Engineering 2002; 124:109-125.

[4] Gong G, Huang X, Wang J, Hao M. An optimized model and test of the China's first high temperature parabolic trough solar receiver. J Solar Energy 2010; 84:2230-2245.

[5] Dudley VE, Kolb GJ, Mahoney AR, Mancini TR, Matthews CW, Sloan M, Kearney D. Test results: SEGS LS-2 solar collector. Sandia Laboratory Report: SAND94-1884; 1994.

[6] Dudley VE, Evans LR, Matthews CW. Test results: industrial solar technology parabolic trough solar collector. Sandia Laboratory Report: SAND94-1117; 1995.

[7] Liu Q, Wang Y, Gao Z, Sui J, Jin H, Li H. Experimental investigation on a parabolic trough solar collector for thermal power generation. Science in China Series E: Technological Sciences; 2010; 53 (1):52-6.

[8] Odeh SD, Morrison GL. Optimization of parabolic trough solar collector system. Int J Energy Research 2006; 30:259-271.

[9] Lüpfert E, Riffelmann KJ, Price H, Burkholder F, Moss T. Experimental analysis of overall thermal properties of parabolic trough receivers. ASME J Solar Energy Engineering 2008; 130:12007-12011.

[10] Burkholder F, Kutscher C. Heat loss testing of Solel's UVAC3 parabolic trough receiver. National Renewable Energy Laboratory Technical Report: NREL/TP-55042394, U.S. Department of Energy, January 2008. 
[11] Burkholder F, Kutscher C. Heat loss testing of Schott's 2008 parabolic trough receiver. National Renewable Energy Laboratory Technical Report: NREL/TP-550-45633, U.S. Department of Energy, May 2009.

[12] Price H, Forristall R, Wendelin T, Lewandowski A, Moss T, Gummo C. Field survey of parabolic trough receiver thermal performance. In: Proceedings of ASME International Solar Energy Conference (ISEC2006), Denver, Colorado, USA.

[13] Forristall R. Heat transfer analysis and modelling of a parabolic trough solar receiver implemented in Engineering Equation Solver. National Renewable Energy Laboratory Technical Report: NREL/TP-550-34169, U.S. Department of Energy, 2003.

[14] He Y, Xiao J, Cheng Z, Tao Y. A MCRT and FVM coupled simulation method for energy conversion process in parabolic trough solar collector. J Renewable Energy 2011; 36: 976-985.

[15] Lüpfert E, Pfänder M, Schiricke B, Eck M. Determination of temperature distribution on parabolic trough receivers. SolarPACES2006; A1-S6.

[16] Munoz J, Abanades A. Analysis of internally helically finned tubes for parabolic trough design by CFD tools. J Applied Energy 2011; 88(11): 4139-4149.

[17] Hegazy AS. Thermal performance of a parabolic trough collector with a longitudinal externally finned absorber. J Heat and Mass Transfer 1995; 31:95-103.

[18] Reddy KS, Ravi Kumar K, Satyanarayana GV. Numerical investigation of energyefficient receiver for solar parabolic trough concentrator. J Heat Transfer Engineering 2008; 29(11):961-972.

[19] Ravi Kumar K, Reddy KS. Thermal analysis of solar parabolic trough with porous disc receiver. J Applied Energy 2009; 86:1804-1812.

[20] Richter C, Teske S, Short R. Concentrating Solar Power - Global Outlook 2009: Why Renewable Energy is Hot. Greenpeace International, SolarPACES and ESTELA: JN 238; 2009.

[21] Price H, Kearney D. Reducing the cost of energy from parabolic trough solar power plants, In: Proceedings of International Solar Energy Conference, Hawaii Island, March 16-18, 2003.

[22] Bejan A. A study of entropy generation in fundamental convective heat transfer. ASME J Heat Transfer 1979; 101:718-725.

[23] Bejan A. Entropy generation minimization: The method of thermodynamic optimization of finite-size systems and finite-time processes. CRC Press; 1996. 
[24] Hooman K, Gurgenci H, Merrikh AA. Heat transfer and entropy generation optimization of forced convection in porous-saturated ducts of rectangular cross-section. Int J Heat and Mass Transfer 2007; 50:2051-2059.

[25] Balaji C, Holling M, Herwig H. Entropy generation minimization in turbulent mixed convection flows. Int. Comm. Heat and Mass Transfer 2007; 34:544-552.

[26] Sahiti N, Krasniqi F, Fejzullahu Xh, Bunjaku J, Muriqi A. Entropy generation minimization of a double-pipe pin fin heat exchanger. J Applied Thermal Engineering 2008; 28:2337-2344.

[27] Ozalp AA. Entropy analysis of laminar-forced convection in a pipe with wall roughness. Int J Exergy 2009; 6(2):249-275.

[28] Amani E, Nobari MRH. A numerical investigation of entropy generation in the entrance region of curved pipes at constant wall temperature. J Energy 2011; 38(11):1-10.

[29] Ilis GG, Mobedi M, Sunden B. Effect of aspect ratio on entropy generation in a rectangular cavity with differentially heated vertical walls. Int Comm Heat and Mass Transfer 2008; 35:696-703.

[30] Mahmud S, Fraser RA. Flow, thermal and entropy generation characteristics inside a porous channel with viscous dissipation. Int J Thermal Sciences 2005; 44:21-32.

[31] Dağtekin İ, Öztop HF, Şahin AZ. An analysis of entropy generation through a circular duct with different shaped longitudinal fins for laminar flow, Int $\mathrm{J}$ Heat and Mass Transfer 2005; 48:171-181.

[32] Parlak N, Gür M, Ari V, Küçük H, Engin T. Second law analysis of water flow through smooth microtubes under adiabatic conditions. J Experimental and Fluid Science 2011; 35:60-67.

[33] Ko TH, Ho CP. A numerical study on entropy generation induced by turbulent forced convection in curved rectangular ducts with various aspect ratios. Int Comm Heat and Mass Transfer 2009; 36:25-31.

[34] Jankowski TA. Minimizing entropy generation in internal flows by adjusting the shape of the cross-section. Int J Heat and Mass Transfer 2009; 52:3439-3445.

[35] Şahin AZ. Irreversibilities in various duct geometries with constant wall heat flux and laminar flow. J Energy 2009; 23(6):465-473.

[36] Le Roux WG, Bello-Ochende T, Meyer JP. Operating conditions of an open and direct solar thermal Brayton cycle with optimised cavity receiver and recuperator. Energy 2011;36:6027-36. 
[37] Le Roux WG, Bello-Ochende T, Meyer JP. Thermodynamic optimisation of the integrated design of a small-scale solar thermal Brayton cycle. Int J Energy Research 2012; 36(11):1088-1104.

[38] Le Roux WG, Bello-Ochende T, Meyer JP. Optimum performance of the small-scale open and direct solar thermal Brayton cycle at various environmental conditions and constraints. Energy 2012; doi:10.1016/j.energy.2012.03.034

[39] Kock F, Herwig H. Local entropy production in turbulent shear flows: a high-Reynolds number model with wall functions. Int J Heat and Mass Transfer 2004; 4:2205-2215.

[40] Herwig H, Kock F. Direct and indirect methods of calculating entropy generation rates in turbulent convective heat transfer problems. J Heat Mass Transfer 2007; 43:207-215.

[41] Moens L, Blake D. Mechanism of hydrogen formation in solar parabolic trough receivers. Technical Report: NREL/TP-510-42468, National Renewable Energy Laboratory, US Department of Energy, 2008.

[42] SCHOTT. SCHOTT PTR ${ }^{\circledR} 70$ Receiver: the next generation, 2009. Available at www.schottsolar.com Last accessed $22^{\text {nd }}$ October 2011.

[43] Versteeg HK, Malalasekera W. An introduction to computational fluid dynamics: the finite volume method. $2^{\text {nd }}$ ed. England: Prentice Hall; 2007.

[44] ANSYS. ANSYS FLUENT Release 13.0 Theory guide, 2010. ANSYS Inc. Southpointe 275 Technology Drive, Canonsburg, PA15317.

[45] Patankar SV, Spalding DB. A calculation procedure for heat, Mass and Momentum transfer in three-dimensional parabolic flows. Int J of Heat Mass Transfer 1972; 15:17871806

[46] Dow. Syltherm 800 heat transfer fluid product technical data, 2001. Available at http://www.dow.com/heattrans. Last accessed $11^{\text {th }}$ June 2012 